\title{
Virus-induced ER stress and the unfolded protein response
}

\section{Lingrui Zhang and Aiming Wang*}

Southern Crop Protection and Food Research Centre, Agriculture and Agri-Food Canada, London, ON, Canada

\section{Edited by:}

James Schoelz, University of

Missouri, USA

\section{Reviewed by:}

Sorina C. Popescu, Boyce

Thompson Institute for Plant

Research, USA

Jeanmarie Verchot, Oklahoma State

University, USA

\section{*Correspondence:}

Aiming Wang, Southern Crop

Protection and Food Research

Centre, Agriculture and Agri-Food

Canada, 1391 Sandford St., London,

ON N5V 4T3, Canada.

e-mail: aiming.wang@agr.gc.ca
The accumulation of unfolded or misfolded proteins in the lumen of the endoplasmic reticulum (ER) results in ER stress that triggers cytoprotective signaling pathways, termed the unfolded protein response (UPR), to restore and maintain homeostasis in the ER or to induce apoptosis if ER stress remains unmitigated. The UPR signaling network encompasses three core elements, i.e., PKR-like ER kinase (PERK), activating transcription factor 6 (ATF6), and inositol-requiring protein-1 (IRE1). Activation of these three branch pathways of the UPR leads to the translation arrest and degradation of misfolded proteins, the expression of ER molecular chaperones, and the expansion of the ER membrane to decrease the load of proteins and increase the protein-folding capacity in the ER. Recently, the essential roles of the UPR have been implicated in a number of mammalian diseases, particularly viral diseases. In virus-infected cells, the cellular translation machinery is hijacked by the infecting virus to produce large amounts of viral proteins, which inevitably perturbs ER homeostasis and causes ER stress. This review summarizes current knowledge about the UPR signaling pathways, highlights two identified UPR pathways in plants, and discuss progress in elucidating the UPR in virus-infected cells and its functional roles in viral infection.

Keywords: virus, endoplasmic reticulum, ER stress, unfolded protein response, signaling transduction

\section{INTRODUCTION}

The endoplasmic reticulum (ER) is a membrane-bound compartment that plays important roles in many cellular processes such as calcium homeostasis and protein processing (Kim et al., 2008; Hetz et al., 2011; Hetz, 2012). Secretory and membrane proteins are synthesized on ribosomes and translocated in an unfolded state into the ER lumen, where they undergo folding, organelle-specific post-translational modifications, and assembly into higher-order structures (Ellgaard and Helenius, 2003; He and Klionsky, 2009; Marcinak and Ron, 2010). As an organelle for folding and modifications of proteins, the ER is loaded with extremely high concentration of proteins $(>100 \mathrm{mg} / \mathrm{ml}$ ), a concentration at which co-aggregation between proteins and/or polypeptides is clearly promoted (Stevens and Argon, 1999). Therefore, the lumen of the ER needs a unique cellular environment that promotes processing and prevents aggregation (Anelli and Sitia, 2008; Kim et al., 2008; Hetz et al., 2011; Hetz, 2012). Indeed, as the major intracellular calcium pool, the ER is the proximal site of a signal transduction cascade that serves to keep cellular homeostasis (Hendershot, 2004; Kim et al., 2008; Hetz et al., 2011; Hetz, 2012). It is also rich in calcium-dependent molecular chaperones (see "Glossary") such as ER luminal binding proteins (BiP), calmodulin (CAM), and calreticulin (CRT), which assist in de novo folding or refolding of proteins with high fidelity (Navazio et al., 2001; Ellgaard and Helenius, 2003; Seo et al., 2008). Furthermore, the ER lumen has an oxidative environment, which is essential for protein disulphide isomerase (PDI)-mediated disulfide formation (see "Glossary"), a process required for the proper folding of a variety of proteins (Kim et al., 2008).
However, the load of client proteins may exceed the assigned processing capacity of the ER due to physiological fluctuations in the demand for protein synthesis and secretion (Zhang and Kaufman, 2006; Ron and Walter, 2007; Marcinak and Ron, 2010; Hetz et al., 2011). The resulting imbalance is referred to as $\boldsymbol{E} \boldsymbol{R}$ stress (Figure 1) (see "Glossary"), which is a pervasive feature of eukaryotic cells (Gao et al., 2008; Liu and Howell, 2010; Marcinak and Ron, 2010; Hetz et al., 2011; Iwata and Koizumi, 2012). In yeast, animals, and plants, ER stress arises under various circumstances (Figure 1), including developmental processes that affect protein homeostasis networks and genetic mutations that erode the functionality of the ER (Brewer and Hendershot, 2004; Schröder and Kaufman, 2005; Balch et al., 2008; Kim et al., 2008; Marcinak and Ron, 2010; Hetz et al., 2011). In fact, a variety of external stimuli (abiotic and biotic stress) such as pathogen invasion, chemical insult, and energy or nutrient (glucose) deprivation have been shown to impose stress on the ER by leading to alterations of cellular redox equilibrium, disturbances of calcium homeostasis, failure of post-translational modifications, and a general increase in protein synthesis (Figure 1) (Dimcheff et al., 2004; Ye et al., 2011; Iwata and Koizumi, 2012). In general, perturbation of ER homeostasis causes unfolded proteins to accumulate in the lumen of the ER, triggering an evolutionarily conserved cytoprotective signaling pathway designated as the unfolded protein response (UPR) (Figure 1) (see "Glossary") (Zhang and Kaufman, 2006; Ron and Walter, 2007; Urade, 2007; Kim et al., 2008).

The initial intent of the UPR is to reestablish homeostasis, relieve stress exerted on the ER, and prevent the cytotoxic impact of malformed proteins via inhibition of mRNA translation and 


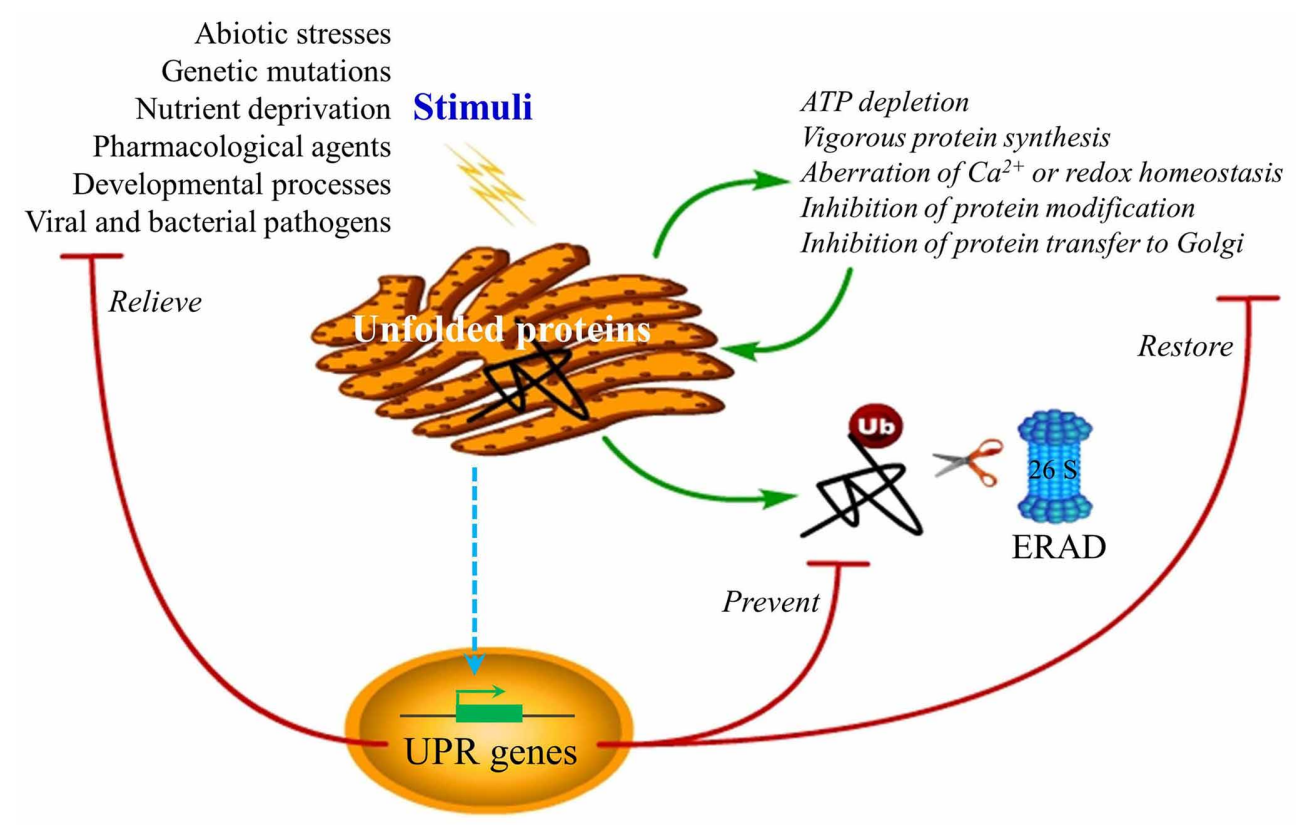

FIGURE 1 | ER stress and UPR functions. Disturbances of ER homeostasis cause overload of unfolded or misfolded protein in the ER lumen, a condition termed ER stress, triggering the UPR. The UPR may be induced by pharmacological chemicals, such as tunicamycin, thapsigargin, homocysteine, reductive/oxidative agents as well as non-steroidal anti-inflammatory agents, which impose stress on the ER by causing the vigorous protein synthesis, the imbalance of $\mathrm{ER} \mathrm{Ca}^{2+}$ and redox, and the inhibition of protein modification or transfer to the Golgi body. In mammalian cells, ER stress also occurs under many circumstances, such as nutrient deprivation, developmental processes, genetic mutation, as well as pathogenic insult. The best-known example of ER stress arising from genetic mutation is the protein-misfolding diseases in human. Recent reports in plants have indicated a close connection between the UPR and environmental stimuli such as heat, salt, and drought stress as well as viral attack, although the underlying mechanisms are largely unknown. The purpose of the induced UPR is to restore the ER function and relive the stress exerted on the ER. In addition, the UPR also eliminates the cytotoxic malformed proteins, which are dislocated across the ER membrane for ubiquitination (Ub) and proteasome-mediated degradation through a pathway known as ERAD. However, if ER homeostasis or function cannot be re-established, programmed cell death will be activated by the UPR, presumably to protect the organism from the rogue cells that display misfolded proteins, which has not yet been confirmed in plants and is not shown in the diagram. activation of adaptive mechanisms (Figure 1) (Xu, 2005; Kim et al., 2008; Preston et al., 2009; Ye et al., 2011). The adaptation effect predominantly refers to the upregulation of particular groups of genes to enhance the protein folding capacity of the ER and to promote ER-assisted degradation (ERAD) (see "Glossary") (Meusser et al., 2005; Kim et al., 2008). The signaltransduction events that are commonly associated with innate immunity and host defense, including mitogen-activated protein kinases (MAPKs), c-Jun N-terminal kinase (JNK), p38, and other kinases responsible for activation of nuclear factor- $\kappa \mathrm{B}(\mathrm{NF}-\kappa \mathrm{B})$, are also induced, known as UPR-induced alarm mechanisms (Kaneko et al., 2003; Xu, 2005; Kim et al., 2008; Tabas and Ron, 2011). However, if the function of the ER cannot be reestablished especially under the conditions when the primary stimuli causing protein unfolding are excessive and/or protracted, a final mechanism called programmed cell death (also apoptosis in animals) (see "Glossary") is triggered, which presumably helps protect the organism from the expansion of potentially harmful substances produced by the damaged cells (Zhao and Ackerman, 2006; Ron and Walter, 2007; Kim et al., 2008; Tabas and Ron, 2011). The ER stress-induced cell death pathway is conserved throughout the plant and animal kingdoms (Urade, 2007; Qiang et al., 2012; Ye et al., 2012). In Arabidopsis thaliana roots, the mutualistic fungus
Piriformospora indica induces ER stress but inhibits the adaptive UPR, resulting in a caspase 1-like mediated cell death, which is required for the establishment of the symbiosis (Qiang et al., 2012).

There is not only an increasing biomedical interest in but also a strong practical demand for investigating the molecular mechanisms underlying the UPR and the development of strategies to manipulate this pathway, due to the fact that chronic ER stress is involved in a number of mammalian diseases including cancers, neurodegeneration, diabetes, inflammation, atherosclerosis, and renal and viral diseases (He, 2006; Zhao and Ackerman, 2006; Yoshida, 2007; Hetz et al., 2011; Tabas and Ron, 2011). The molecular mechanism of the UPR has been investigated extensively in yeast and animals and to a much lesser extent in plants (Cox and Walter, 1996; Sidrauski and Walter, 1997; Oikawa et al., 2010). In mammalian cells, the UPR is mediated by two types of ER transmembrane proteins (ER stress sensors). The type I ER stress sensor consists of IRE1 (inositol-requiring transmembrane kinase/endonuclease) including two identifiable IRE1 isoforms IRE1 $\alpha$ and IRE1 $\beta$, and PERK (PKR-like ER kinase), whereas the type II ER stress sensor includes ATF6 $\alpha$ and ATF6 $\beta$ (activating transcription factor 6) (Hetz et al., 2011). In contrast to animals, the UPR in yeast is controlled by only one 
signaling pathway, the type I transmembrane ER protein IRE1p (Cox and Walter, 1996; Sidrauski and Walter, 1997; Oikawa et al., 2010).

In the past several years, the plant UPR signaling pathway has begun to be explored (Urade, 2007; Vitale and Boston, 2008; Deng et al., 2011; Nagashima et al., 2011). Thus far, two UPR pathways have been identified in plants, one mediated by IRE1-bZIP60 (basic leucine zipper), and the other by bZIP17/bZIP28 which is analogous to the animal ATF6 pathway (Urade, 2007; Vitale and Boston, 2008; Deng et al., 2011; Nagashima et al., 2011). In addition, an adaptive pathway mediated by plant-specific $\mathrm{N}$-rich proteins, which diverges from the molecular chaperone-inducing branch of the UPR, was described as a novel branch of the ER stress response in plants that shares components with the osmotic stress signaling (Costa et al., 2008). Much of the work in plants has concentrated on ER stress induced by environmental cues (Iwata and Koizumi, 2012). For instance, in response to heat stress, two UPR pathways were found to be activated, indicated by bZIP28 proteolytic activation and bZIP60 mRNA splicing (Gao et al., 2008; Deng et al., 2011). The UPR and salt or drought stress have drawn attention from several laboratories (Irsigler et al., 2007; Liu et al., 2007; Costa et al., 2008; Liu and Howell, 2010). More recently, the essential role of the UPR in plants in response to viral attack has also been investigated (Ye and Verchot, 2011; Ye et al., 2011, 2012). In this review, we summarize in detail the current proposed models of how the ER transmembrane proteins sense the unfolded settings, and then address primarily the mechanistically distinct arms of the UPR as well as their relevance to viral infection in animals and plants. Some UPR related proteins such as cellular chaperons and folding enzymes may directly participate in the formation of membrane bound replication and movement complexes. Interested readers may refer to another review published in this special issue (Verchot, 2012). Finally, we discuss possible future directions of research on plant UPR, especially its roles in viral infection.

\section{BiP: THE SUPPRESSOR OF THE UPR?}

It is generally accepted that signaling in the UPR is initiated by UPR stress sensors, which are ER resident transmembrane proteins. They utilize their luminal portions to sense the proteinfolding environment in the ER, and their cytoplasmic effector portions to interact with the transcriptional or translational apparatus (Ron and Walter, 2007). To date, several models have been proposed to explain how the unfolded protein load is detected by ER stress transducers (UPR stress sensors) to initiate the UPR activation (Parmar and Schröder, 2012).

\section{INDIRECT RECOGNITION MODEL}

The ER chaperone immunoglobulin heavy-chain BiP, also known as glucose-regulated protein 78 (GRP78), has been proposed as a master repressor of UPR (Hendershot, 2004; He, 2006; Zhang and Kaufman, 2006; Parmar and Schröder, 2012). It has been long known that BiP is more strongly induced by slowly folding proteins with a prolonged interaction with BiP than fast folding proteins (Gething et al., 1986; Watowich et al., 1991; Kohno et al., 1993). In normal cells, BiP keep UPR stress sensors in their inactive monomeric states through binding to their luminal domains (Figure 2A). Conversely, in cells undergoing ER stress, $\mathrm{BiP}$ is released when sequestered by unfolded proteins, leading to the activation of these ER stress sensors (Figure 2A) (Parmar and Schröder, 2012). Pivotal evidence for this chaperon-mediated model (indirect recognition model) comes from immunoprecipitation assay directly showing that, in unstressed acinar and fibroblasts cells, the luminal domains of PERK and IRE1 form a stable complex with the ER chaperone BiP, and the perturbation of protein folding promotes reversible dissociation of BiP from these two type-I transmembrane protein kinases, which correlates with the formation of activated PERK or IRE1 (Bertolotti et al., 2000). Consistently, in CHO cells stably overexpressing $\mathrm{BiP}$, the amount of BiP being associated with PERK or IRE1 is considerably greater than that in parental $\mathrm{CHO}$ cells with normal levels of endogenous BiP (Bertolotti et al., 2000). Moreover, in BiP-overexpressing $\mathrm{CHO}$ cells, phosphorylation of PERK is delayed and incomplete, and activation of IRE1 $\alpha$ by ER stress is absent (Dorner et al., 1992; Wang et al., 1996; Bertolotti et al., 2000). In fact, the UPR is attenuated by overexpression of only BiP rather than of other UPR molecular signatures (Dorner et al., 1990, 1992). As for the type-II transmembrane transducer, overexpression of wild-type BiP dramatically delays the translocation of ATF6 to the Golgi and leads to the lower amount of cleaved ATF6 in dithiothreitol (DTT)-treated Hela cell (Shen et al., 2002). A BiP mutant that bears a point mutation in its ATPase domain and loose ability to dissociate from ATF6 completely abolishes DTT-induced ATF6 activation (Shen et al., 2002). Collectively, these data suggest that the mechanisms of ER stress sensing by type-I transmembrane sensors may also operate in the control of type-II transmembrane sensor activation.

\section{SEMI-DIRECT RECOGNITION MODEL}

However, the indirect recognition model is challenged by an observation in yeast that deletion of the BiP-binding site renders IRE1p unaltered in ER stress inducibility, although it abolishes BiP binding (Kimata et al., 2004). The crystal structure of the yeast IRE1p luminal domain suggests that an IRE1p dimer creates a shared central groove formed by $\alpha$-helices, with an architectural resemblance to the peptide binding domains of major histocompatibility complexes (MHCs) (see "Glossary") (Credle et al., 2005; Parmar and Schröder, 2012). Thus, IRE1 itself has the intrinsic ability to sense ER stress, and its activation may be initiated by BiP dissociation and further triggered by binding of unfolded proteins to its luminal domains (Figure 2B) (Kimata et al., 2004). This two-step activation model (semi-direct recognition model, Figure 2B) is proposed considering findings that BiP mutants locked in the ATP-bound state, but not the ADPbound state interact with IRE1 (Kimata et al., 2003). Analysis of mutation in BiP ATPase domain further revealed that the conformational change in $\mathrm{BiP}$ induced by the binding of unfolded proteins to ATP-bound BiP leads to ATP hydrolysis, conversion of $\mathrm{BiP}$ to the ADP-bound state and release from IRE1 (Kimata et al., 2003; Todd-Corlett et al., 2007). This model is also supported by the fact that recombinant luminal domains of the yeast IRE1p is associated with unfolded proteins in a cell-free system (Kimata et al., 2007). However, this model remains controversial as there 

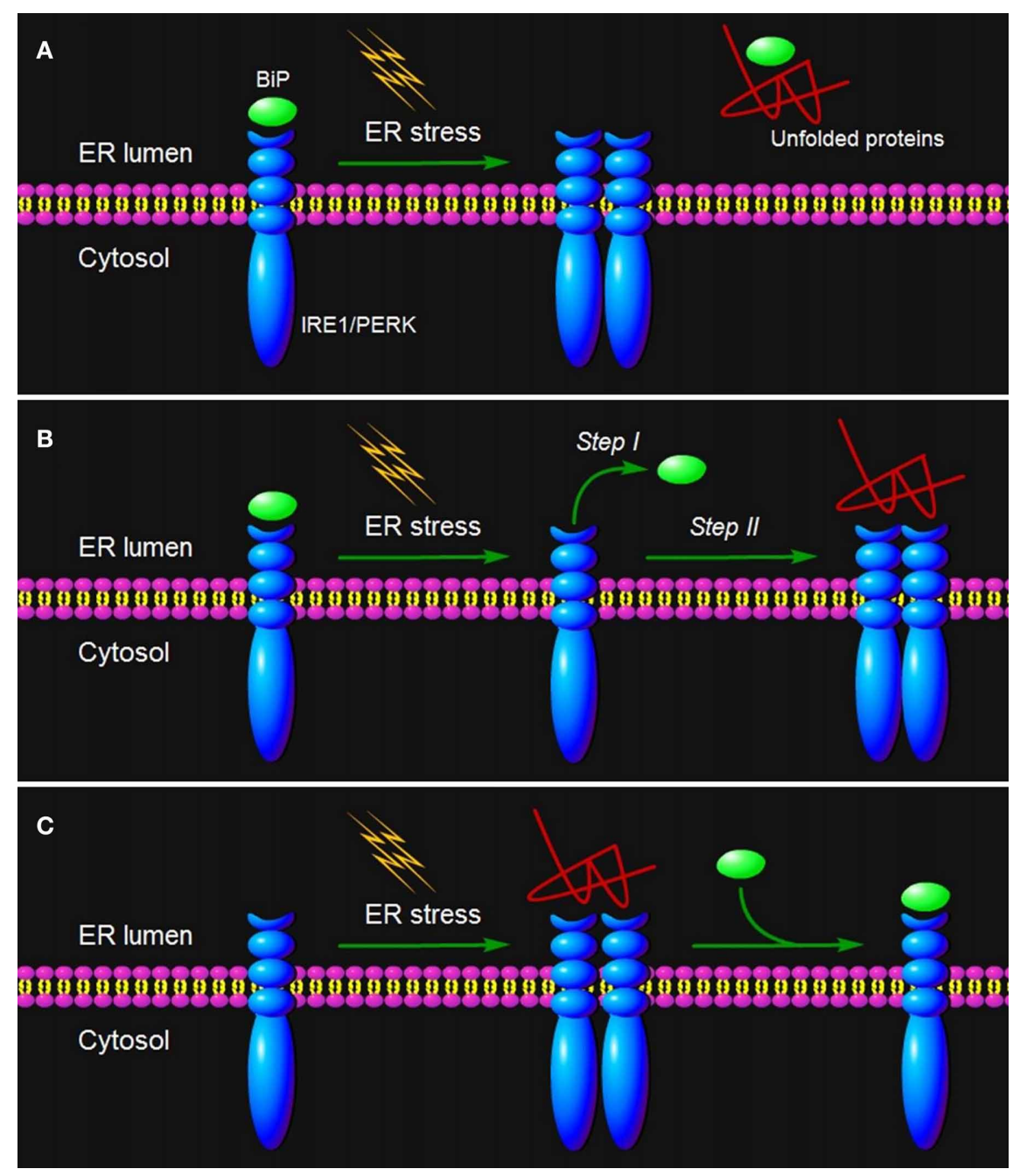

FIGURE 2 | ER stress sensing mechanism by IRE1/PERK. Three models are proposed to explain IRE1/PERK activation in response to the accumulation of unfolded proteins in the ER lumen. (A) The indirect recognition model proposes that BiP binding maintains IRE1/PERK in an inactive monomeric state. During ER stress, BiP is dissociated from its partners to bind unfolded proteins, which leads to the spontaneous dimerization of IRE1/PERK and activation of their RNase domains. In this case, BiP operates as the "UPR master control/ER stress sensor." The model may also operate in the control of ATF6 activation. (B) The semi-direct recognition model summarizes findings from studies of IRE $1 p$ in yeast and analyses of IRE1 crystal structure. This model proposes that the IRE1 is activated via two steps. In the first step, BiP dissociation from IRE1 leads to formation of higher order oligomers (called cluster). In the second step, direct interaction of unfolded proteins with IRE1 stabilizes the cytosolic domains of clustered IRE1 molecules and thus causes IRE1 activation. (C) A direct recognition model outlines recent studies in yeast. Three subpopulations of IRE1p co-exist within the cell: an inactive pool in equilibrium with an active unfolded protein-bound pool. The latter is sequestered by BiP binding, designated the third inactive set. In this model, BiP binding to or release from IRE1p does not activate the UPR, but it may serve as a buffer and a timer to adjust the sensitivity and dynamics of IRE1p activity. In turn, the unfolded protein binding to IRE1 is the single step of its activation. lacks evidence that unfolded proteins bind to IRE1 in vivo, and there is no time-course analysis of BiP dissociation and binding of unfolded proteins to IRE1.

\section{DIRECT RECOGNITION MODEL}

Recently, based on time-resolved analysis of IRE1p signaling in yeast, Peter Walter's group has proposed a new quantitative model (direct recognition model, Figure 2C). In this dynamic UPR regulation model, IRE1 is in a dynamic equilibrium with BiP and unfolded proteins, and the unfolded protein binding to IRE1 is the single and sufficient step for activation of the UPR (Pincus et al., 2010). BiP binding to or release from IRE1 is ruled out as the primary switch that governs the UPR on or off as previously proposed, and it might act as a buffer and a timer to fine-tune the sensitivity and dynamics of the UPR, respectively (Figure 2C) (Pincus et al., 2010). The direct recognition model is strengthened by elegant biochemical assays showing that unfolded proteins are IRE1p-activating ligands that could directly induce the UPR in yeast cells (Gardner and Walter, 2011). Binding of unfolded proteins to IRE1 monomers induces dimerization via formation of the MHC-like peptide binding groove (Credle et al., 2005; Gardner and Walter, 2011). Moreover, considerable data suggest 
that the cluster formation is a prerequisite for signaling by IRE1 (Credle et al., 2005; Kimata et al., 2007; Aragón et al., 2008; Korennykh et al., 2008). Nevertheless, the recombinant luminal regions of human IRE1 do not interact with unfolded proteins in a cell-free system (Oikawa et al., 2009), consistent with a previous prediction that, unlike yeast IRE1p, the MHC-like groove in the crystal structure of human IRE1 is too narrow for peptide binding (Zhou et al., 2006).

The difference in IRE1 structure between yeast and human reminds us that the complexity of ER stress sensing is far beyond our understanding and that structure-functional analysis in this field is far from complete. In the case of plants, the Arabidopsis and rice IRE1 proteins are the ER-resident proteins that possess kinase activity and have ability to sense ER stress with their luminal domain (Iwata and Koizumi, 2012). Although it has been known that overexpression of $\mathrm{BiP}$ in tobacco and soybean prevents activation of the UPR by ER stress inducers (LeborgneCastel et al., 1999; Costa et al., 2008), the underlying mechanisms of ER stress sensing by plant IRE1 have not been investigated.

\section{VIRAL INFECTION AND ER SENSING}

In the recent decades, the importance of ER stress and UPR response in viral infection has been demonstrated in mammalian cells (Jordan et al., 2002; Baltzis et al., 2004; Netherton et al., 2004; Sun et al., 2004; Tardif et al., 2005). In a productive viral infection, large amounts of viral proteins are synthesized in infected cells, which lead to an overwhelming load of unfolded or misfolded proteins (Kim et al., 2008). Many mammalian viruses have evolved to manipulate host UPR signaling pathways to promote viral translation and persistence in infected cells. For example, flaviviruses such as Japanese encephalitis virus (JEV) and dengue viruses (DEN) trigger the specific UPR pathway, leading to enhanced protein folding abilities (Urano et al., 2000). Early studies with hemagglutinin-neuroamindase (HN) (see "Glossary") glycoproteins of influenza virus revealed that BiP associates transiently and non-covalently with the unfolded or immature glycoproteins (Hurtley et al., 1989). The misfolded, BiP-associated glycoproteins are not transported to the plasma membrane but persist as complexes in the ER for a long period of time before degradation (Hurtley et al., 1989). Similar observations have been reported with glycoprotein $G$ of vesicular stomatitis virus, HN glycoproteins of paramyxovirus SV5, and glycoprotein of hepatitis C virus (HCV) (Ng et al., 1989; Machamer et al., 1990; Choukhi et al., 1998). Taken together, these data support the model in which interaction of BiP with unfolded viral proteins triggers the UPR response during viral infection.

Intriguingly, among 7 proteins encoded by simian virus 5, only the HN glycoprotein stimulates UPR response (Hurtley et al., 1989; Watowich et al., 1991). In virus-infected cells, the HN glycoprotein is inserted into the ER, and then transported to cell surface (He, 2006). Similarly, ectopic expression of the E2 protein, but not E1, core and NS3 proteins of HCV activates the expression of BiP (Liberman et al., 1999). HCV replicons expressing only non-structural proteins are also capable of stimulating BiP expression (Tardif et al., 2002). Infection of cytomegalovirus (CMV) causes a transient increase in BiP levels at the early phase of viral replication. Moreover, the expression of CMV Us11 that physically interacts with $\mathrm{BiP}$ in mammalian cells is sufficient to trigger the UPR (Tirosh et al., 2005). In addition, several other studies have also suggested a connection between the UPR and viral replication. These include herpes simplex virus (HSV) 1, JEV, and HCV (Su et al., 2002; Cheng et al., 2005; Tardif et al., 2005). These studies suggest that either the process of viral replication or the production of a specific viral protein in the ER is capable of inducing UPR response.

Although how ER stress sensors sense viral infection to activate the UPR is not clear, a recent study with severe acute respiratory syndrome (SARS) coronavirus (SARS-CoV) has identified one of accessory proteins of SARS-CoV, the $8 \mathrm{ab}$ protein that could bind directly to the luminal domain of ATF6, the type II ER stress sensor (Sung et al., 2009). Ectopic expression of the $8 \mathrm{ab}$ protein in mammalian cells induces the proteolysis of ATF6 and the translocation of its cleaved DNA-binding and transcription-activation domains from the ER to nucleus (Sung et al., 2009). These findings suggest that viruses may exploit their own protein(s) to directly modulate UPR response.

As has been reported for animals, the most prominent phenomenon in plants induced by the UPR is the transcriptional induction of ER chaperone and protein-folding genes, such as BiP, CRT, and PDI (Schott et al., 2010). Recently, Arabidopsis stromalderived factor 2 (SDF2) was identified as a crucial target of the plant UPR with a direct function in ER protein quality control (Schott et al., 2010). Using a combination of biochemical and cell biological methods, SDF2 was shown to respond to ER stress conditions and pathogen infestation in a manner similar to known molecular UPR markers (Wang et al., 2005; Schott et al., 2010). In plants, microarray-based analyses of gene expression have shown that $\mathrm{BiP}$ is upregulated in Arabidopsis in response to infections by Turnip mosaic virus (TuMV) and Oilseed rape mosaic virus (ORMV) (Whitham et al., 2003; Yang et al., 2007; García-Marcos et al., 2009). Similar upregulation of ER-resident chaperones has also been found in Arabidopsis and potato (Solanum tuberosum) during Potato virus X (PVX) infection (Whitham et al., 2003; Yang et al., 2007; García-Marcos et al., 2009). In PVX infection, a viral movement protein TGBp3, which resides in the ER, elicits the UPR in Arabidopsis and Nicotiana benthamiana as an early response to virus infection (Ye and Verchot, 2011; Ye et al., 2011). Similar to the ER-resident proteins encoded by flaviviruses or retroviruses such as HIV (Tardif et al., 2004; Chan and Egan, 2005; Sung et al., 2009), TGBp3 modulates the UPR signaling as a means to cope with robust viral protein synthesis (Ye and Verchot, 2011; Ye et al., 2011). In the case of HIV, the Vpu protein coded by HIV has been shown to trigger the degradation of the host CD4 protein by the $26 \mathrm{~S}$ proteasome, and this degradation is vital for virion release (Schubert et al., 1998; Meusser et al., 2005; Nomaguchi et al., 2008). Considering the similarity of TGBp3 to Vpu in terms of molecular mass and subcellular localization, TGBp3 may have analogous functions to Vpu in targeting host proteins for ubiquitination and degradation to ensure virus spread (Ye et al., 2012). In addition, the TGBp3-elicited UPR effectively delays the host immune responses to aid PVX infection, including TGBp3-triggered programmed cell death (Ye et al., 2012). The induction of cell death pathway can be suppressed by 
overexpression of $\mathrm{BiP}$ and is dependent on SKP1, a core subunit of the SCF (SKP1/Cullin1/F-box protein) ubiquitin E3 ligase complex (Ye et al., 2012). However, the mechanisms of the activation of the UPR by TGBp3 in PVX infection or by other viral proteins (if any) in infections by other plant viruses as well as the roles of the chaperone $\mathrm{BiP}$ in governing the UPR in virus-infected plants still remain unknown.

\section{THREE PATHWAYS OF THE UPR PERK PATHWAY AND PROTEIN SYNTHESIS CONTROL}

PERK is a ER-localized type I transmembrane protein, with a catalytic kinase domain sharing substantial homology to other kinases of the eukaryotic translation initiation factor 2 (eIF2) (see "Glossary") (Harding et al., 1999). In the early phase of ER stress, accumulation of unfolded or misfolded protein leads to oligomerization of PERK in the ER membranes, inducing its trans-autophosphorylation and kinase domain activation
(He, 2006; Kim et al., 2008). ER stress-activated PERK phosphorylates eIF $2 \alpha$ on Ser51, which inhibits the guanine nucleotide exchange factor eIF2B from recycling eIF2 to its active GTPbound form (Figure 3). As a result, mRNA translation is shut off and the load of newly synthesized proteins is reduced that are destined to enter the already stressed ER lumen (Figure 3) (Hetz et al., 2006). An exceptional case to this general response is that certain mRNAs gain a selective advantage for translation under conditions in which eIF2 $\alpha$ is phosphorylated (Figure 3) (Lu et al., 2004). The $5^{\prime}$ untranslated region of these mRNA contains short, inhibitory upstream open reading frames (uORFs) that prevent translation of their downstream encoding ORF in unstressed cells. When eIF $2 \alpha$ activity is limited due to its phosphorylation in stressed cells, ribosomes skip the inhibitory uORFs so that they can be translated (Ron and Walter, 2007). Two of such genes that have been extensively studied include the transcription factor Gcn4 (general control non-depressible-4) in yeast and

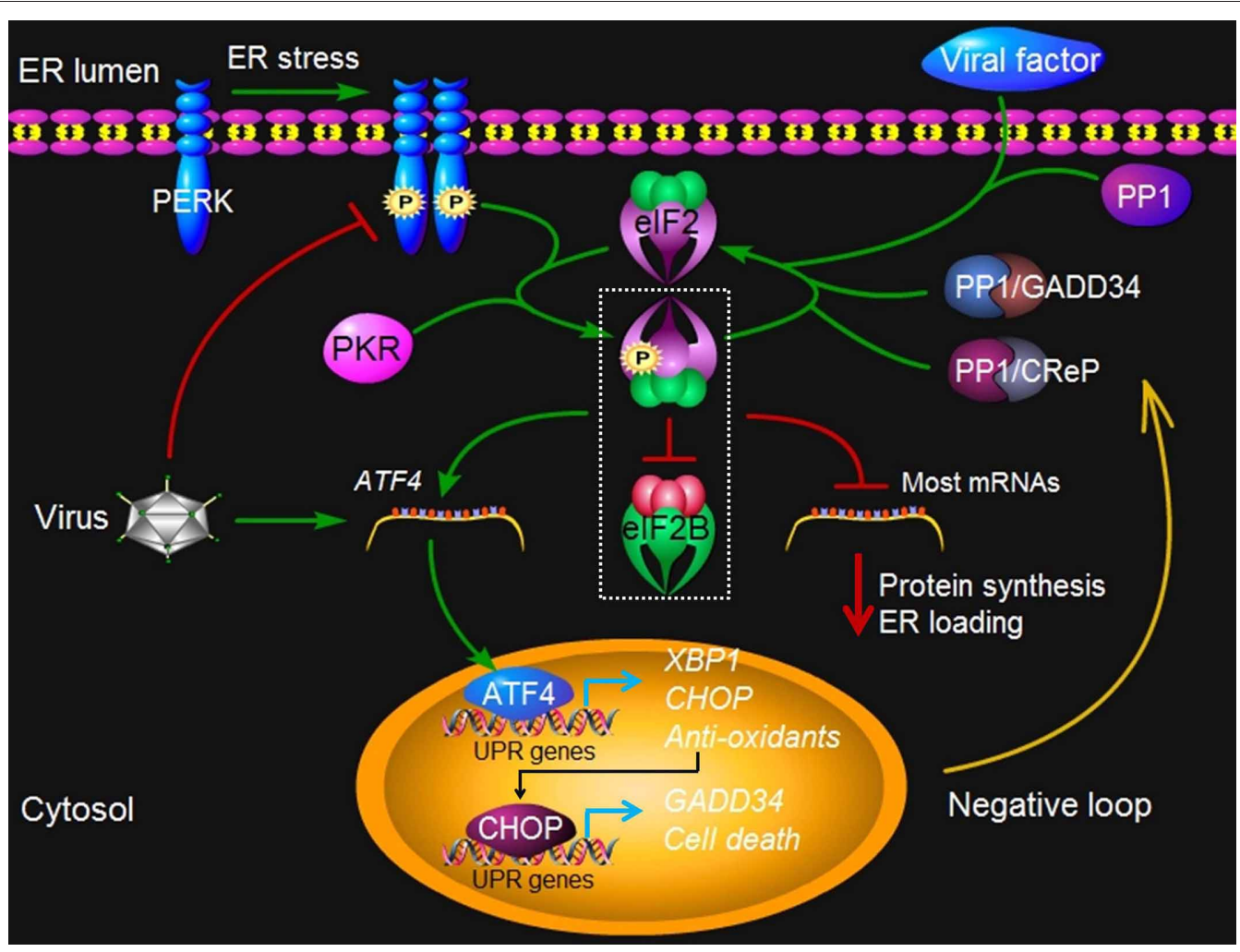

FIGURE 3 | PERK signaling under virus attack. Upon ER stress such as virus infection, protein kinase PERK oligomerizes in the ER membrane and is activated via trans-autophosphorylation. The activated PERK phosphorylates a subunit of elF2, which inhibits the exchange factor elF2B from recycling elF2 to its active GTP-bound form. In addition, dsRNA-activated protein kinase $R$ (PKR) can also activate this pathway independently of PERK. The resulting reduced activities of elF2B and the elF2 complex account for all of the important consequences of PERK activity, such as translation inhibition of most mRNAs, which reduces protein synthesis and lowers ER loading. However, some mRNA such as ATF4 gains a selective advantage for translation via phosphorylated elF2. ATF4 in turn contributes to the transcriptional activation of $C H O P, X B P 1$, GADD34, and other genes involved oxidative stress and cell death.
GADD34 is a regulatory subunit of protein phosphatase (PP) 1 that dephosphorylates elF2 $\alpha$ and recovers the activity of elF2, constituting a negative feedback loop for regulation of PERK signaling. A constitutive phosphatase CreP also promotes elF2 dephosphorylation. Viruses such as CMV may directly exploit the negative loop to terminate the PERK signaling pathway, via increasing the expression of ATF4, because the prolonged closure of protein synthesis is harmful to virus infection. Some viruses, such as HSV1 and ASFV, may produce a viral factor, which is homologous to host GADD34, to restore the activity of elF2 along with PP1. Other viruses such as HCV may encode a viral protein that binds to PERK as a pseudosubstrate and thus, inhibits PERK activation. Finally, viruses such as LCMV may selectively activate the branches of the UPR to favor their replication. At present, no PERK-like pathway has been found in plants. 
ATF4 in mammalian cells (Figure 3) (Hinnebusch and Natarajan, 2002; Lu et al., 2004; Vattem and Wek, 2004). ATF4 is responsible for stimulating the expression of a pro-apoptotic factor C/EBP homologous protein $(\mathrm{CHOP})$, as well as growth arrest and DNA damage-inducible protein 34 (GADD34) (Figure 3) (Zinszner et al., 1998; Novoa et al., 2003).

A chemical inhibitor that sustains phosphorylation of eIF2 $\alpha$ protects rat pheochromocytoma cell from ER stress, suggesting that the maintenance of $\operatorname{IF} 2 \alpha$ in an inactive state is somehow beneficial to cell survival during the circumstances that induce ER stress (Boyce et al., 2005). However, prolonged suppression of protein synthesis is typically incompatible with cell survival (Ron and Walter, 2007; Kim et al., 2008). Although the regulatory mechanisms and the phosphatase(s) involved are yet to be characterized, it has been reported that ER stress-induced PERK activation in pancreatic AR42J cells is rapidly reversible, and, upon removal of ER stress, activated PERK is dephosphorylated (Bertolotti et al., 2000; Jousse et al., 2003). In fact, it is well known that phosphorylated eIF2 $\alpha$ is also subject to negative regulation (Ron and Walter, 2007). Somatic-cell genetic screen has identified two genes GADD34 and CReP (constitutive repressors of eIF2 $\alpha$ phosphorylation) encoding the substrate targeting subunits of two phosphatase complexes that independently dephosphorylate eIF2 $\alpha$ (Figure 3) (Connor et al., 2001; Jousse et al., 2003; Ma and Hendershot, 2003). CReP is constitutively expressed and contributes to baseline eIF2 $\alpha$ dephosphorylation, whereas GADD34 is induced as part of the gene expression program activated by eIF2 $\alpha$ phosphorylation and serves in a negative feedback loop that regulates eIF2 $\alpha$ activity (Figure 3) (Jousse et al., 2003; Novoa et al., 2003).

In mammalian cells, a considerable body of evidence has indicated the association of viral replication with the PERK pathway (Jordan et al., 2002; Baltzis et al., 2004; Netherton et al., 2004; Sun et al., 2004; Boyce et al., 2005; Cheng et al., 2005; Isler et al., 2005). It becomes clear that the battle between the invading virus and the host cell in the ER is complicated. The repair of the ER function offered by PERK activation is beneficial to viral replication (He, 2006). On the other hand, the inhibition of protein synthesis mediated by the PERK pathway conversely regulates viral replication and maturation as all viruses depend on the cell translation machinery to synthesize viral proteins. Then one may wonder how viruses manage to overcome the translation inhibition imposed by the PERK pathway for the high speed production of viral proteins required for virus multiplication.

In human and mouse cells infected with the DNA virus HSV1, the production and processing of viral proteins in the ER presumably trigger the oligomerization of PERK, leading to the activation of PERK, as estimated by an increase in autophosphorylation of PERK (Cheng et al., 2005). Interestingly, in these cells with activated PERK, eIF2 $\alpha$ remains in the unphosphorylated state, and viral polypeptide synthesis is thus normal. Obviously, the virus stimulates and then disarms the PERK activity. A virulence factor, the $\gamma 134.5$ protein encoded by HSV1, has been shown to have a critical role in mediating eIF $2 \alpha$ dephosphorylation in virus-infected cells (Figure 3) (He et al., 1997; Cheng et al., 2005). Furthermore, the $\gamma 134.5$ protein can alleviate the translation arrest caused by the UPR inducing compounds DTT and thapsigargin (He et al., 1997; Cheng et al., 2005). Importantly, the $\gamma 134.5$ protein also inhibits the activity of double-stranded RNAdependent protein kinase R (PKR) by mediating eIF2 $\alpha$ dephosphorylation (Figure 3) (He et al., 1997, 1998; Cheng et al., 2001). Indeed, the carboxyl-terminal domain of viral $\gamma 134.5$ protein is highly homologous to the corresponding region of GADD34, suggesting the domain shared by the two proteins may perform a common function (He et al., 1997; Cheng et al., 2005). Like GADD34, the $\gamma 134.5$ protein can recruit protein phosphatase 1 to dephosphorylate eIF $2 \alpha$ and block translation shutoff during viral infection (Figure 3) (He et al., 1997; Cheng et al., 2005). Together, these findings suggest that the viral protein $\gamma 134.5$ functions as an antagonist to the inhibitory activity of the PERK pathway on protein translation by maintaining the eIF2 activity during a productive HSV1 infection.

Although ER stress and the UPR are evident in the course of productive infection by African swine fever virus (ASFV, DNA virus), PERK activation seems not to be induced (Galindo et al., 2012). In Vero (African green monkey kidney) cells infected by ASFV, the eIF $2 \alpha$ phosphorylation is maintained at a lower level in order to restore protein translation (Galindo et al., 2012). Furthermore, ASFV is capable of blocking the expression of CHOP induced by DTT, thapsigargin, and other agents (Netherton et al., 2004). ASFV also encodes the viral protein DP71L, a homolog to GADD34 (Zsak et al., 1996). However, it is not clear if DP71L also involves in the inhibition of PERK activation.

It is well documented that the human DNA virus CMV perturbs the PERK pathway (Netherton et al., 2004; Isler et al., 2005; Tirosh et al., 2005). Unlike HSV1, CMV replicates slowly and in an ordered temporal manner. It seems that CMV directly exploits the cellular negative feedback loop to inhibit PERK activities. In human foreskin fibroblasts (HFFs) cells infected with CMV, PERK is not phosphorylated in the early phase. As viral replication proceeds, there is an increase in the level of PERK phosphorylation. However, the amount of phosphorylated eIF2 $\alpha$ is limited and translation attenuation does not occur (Netherton et al., 2004; Isler et al., 2005; Tirosh et al., 2005). Interestingly, translation of ATF4, which is dependent on eIF2 $\alpha$ phosphorylation, is significantly increased (Netherton et al., 2004; Isler et al., 2005; Tirosh et al., 2005). Expression of ATF4 leads to the activation of target genes involved in the maintenance of metabolism and redox state, and thus may benefit CMV infection by maintaining a permissive cellular environment (Figure 3). It is worth to note that ATF4-induced GADD34 can act directly downstream of eIF $2 \alpha$ phosphorylation to eliminate the negative effects of PERK activation (Figure 3) (Jousse et al., 2003; Novoa et al., 2003).

The PERK pathway is also associated with infections by RNA viruses. For example, a cytopathic strain of bovine viral diarrhea virus (BVDV), a member of flaviviruses, activates PERK and causes hyperphosphorylation of eIF2 $\alpha$ (Jordan et al., 2002). However, it remains unclear as to how the translation attenuation resulting from PERK activation is overcome by BVDV. HCV encodes a viral E2 protein, which binds to PERK as a pseudosubstrate and may sequester it from its normal substrate eIF2 $\alpha$ (Figure 3) (Pavio et al., 2003). Consistently, ectopic 
expression of the E2 protein inhibits PERK phosphorylation and enhances translation, contributing to a persistent HCV infection. Additionally, viruses such as LCMV (lymphocytic choriomeningitis virus) bypass the PERK pathway to selectively activate the ATF6 pathway (Pasqual et al., 2011). Therefore, different viruses may adapt different strategies to cope with the PERK pathway for a productive infection. To date, no genes homologous to the animal PERK have been found in plants. It is reasonable to speculate that plants do not have the PERK pathway (Iwata and Koizumi, 2012).

\section{IRE1 PATHWAY AND PROTEIN DEGRADATION}

IRE1, the first UPR transducer identified by a mutation screen in yeast, is a bifunctional enzyme, i.e., a Ser/Thr protein kinase and a site-specific carboxyl-terminal endoribonuclease. Like PERK, IRE1 has an ER luminal amino-terminal domain and a transmembrane domain that anchors IRE1 to the ER membrane (Figure 4) (He, 2006). In response to ER stress, IRE1 is activated directly and/or indirectly by unfolded proteins as mentioned earlier. Unlike PERK, IRE1 signaling does not have selected downstream kinase targets because the only known substrate of the IRE1 kinase is IRE1 itself (Shamu and Walter, 1996; Papa et al., 2003). Trans-autophosphorylation of the kinase domain of IRE1 activates its unusual effector function that catalyzes the unconventional processing (see "Glossary") of the only known substrate (Figure 4): an mRNA that encodes a UPR transcriptional activator named Hacl (homologous to ATF/CREB1) in yeast (Cox and Walter, 1996; Mori et al., 1996) or XBP1 (X-box BiP-1) in metazoans (Yoshida et al., 2001; Calfon et al., 2002).

The precursor XBP1 or Hacl mRNA is cut twice by the activated IRE1, and a 26 nucleotide intron of $x b p 1$ mRNA is spliced out (Hetz et al., 2011). The $5^{\prime}$ and $3^{\prime}$ mRNA fragments are then re-ligated, producing a spliced mRNA that encodes a $41 \mathrm{kDa}$ XBP1 protein, a bZIP family transcription factor (Figure 4) (Sidrauski et al., 1996; Stephens et al., 2005; Kim et al., 2008). The spliced version of XBP1 (termed XBP1s) upregulates a general population of UPR-related genes mainly involved in protein folding and ERAD (Figure 4) (Lee et al., 2003; Shaffer et al., 2004). Thus, the IRE1-XBP1 pathway directs both protein refolding and degradation in response to ER stress. Recently, the IRE1dependent degradation of ER-associated mRNAs has also been observed in ER-stressed Drosophila melanogaster cells (Hollien and Weissman, 2006; Hollien et al., 2009), allowing to propose

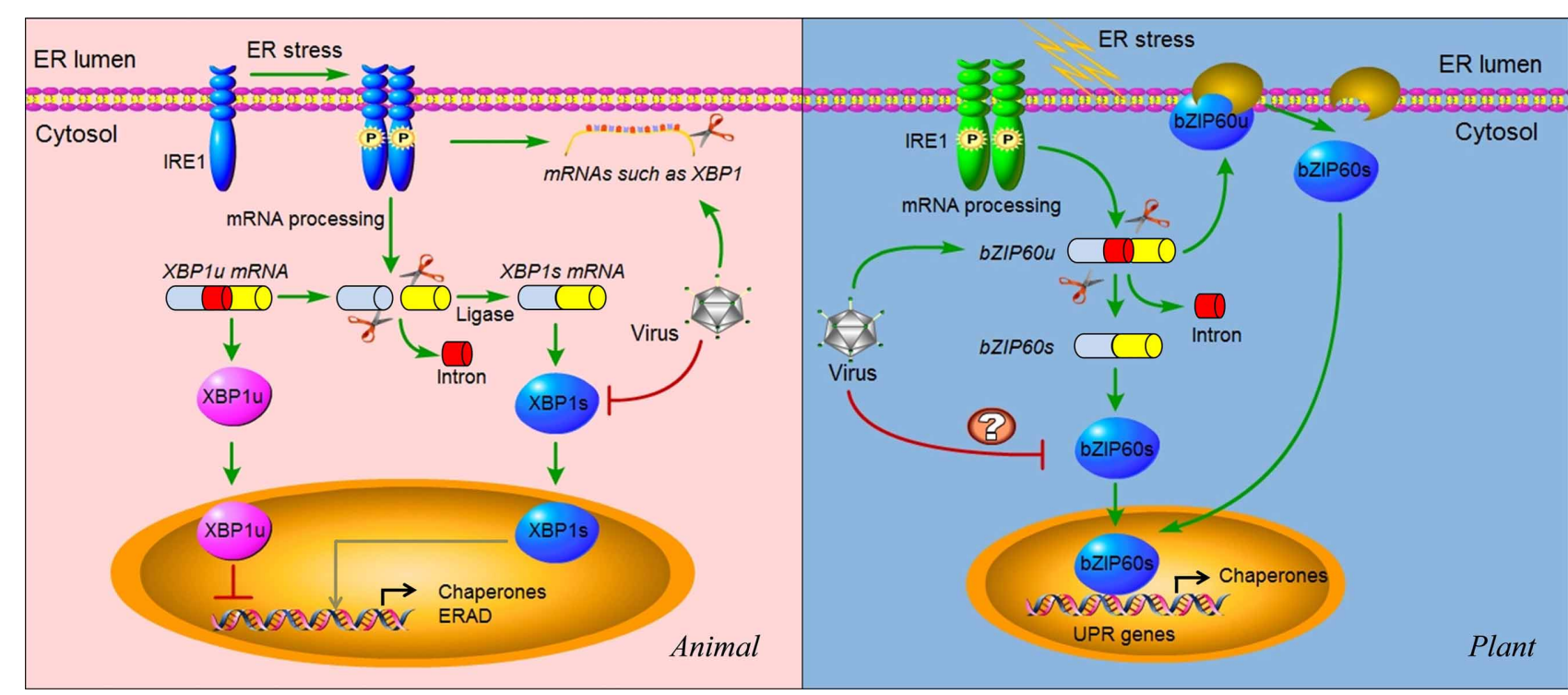

FIGURE 4 | IRE1 signaling and virus infection in animals and plants. In animals, IRE1 oligomerizes in the plane of the ER membrane in stressed cells, leading to trans-autophosphorylation and activation. Activated IRE1 mediates the sequence-specific cleavage of the XBP1 mRNA in higher eukaryotes, deleting a small RNA fragment (intron) and finally producing a spliced mRNA (XBP1s) with a frame shift in the coding sequence. Spliced $X B P 1 s$ encodes a potent transcriptional activator (XBP1s), whereas the unspliced XBP1 mRNA (XBP1 $u$ ) encodes an inhibitor of the UPR (XBP1 1 ). In mammals, it seems that XBP1s regulates a subset of UPR genes that promote ERAD of misfolded proteins and refold proteins. In cultured Drosophila melanogaster cells, activated IRE1 can promote the cleavage of mRNAs, including XBP1 mRNA, leading to their degradation. This reduces the load on the stressed ER and might facilitate reprogramming of the ER-associated protein synthesis and translocation machinery. In cells infected by viruses such as HCV, the IRE1 pathway is manipulated by the virus via repressing the transcriptional activity of XBP1s. In addition, some viruses might also promote the IRE1-dependent mRNA decay as a means to manipulate the IRE1 pathway. In plants, IRE1 homologs were detected in the genomes of Arabidopsis and rice a decade ago. However, the target of IRE1 was not identified until 2011. The mRNA of transcriptional factor bZIP60 is the substrate of IRE1 in plants. Similar to XBP1 in animals, unspliced bZIP60 (bZIP60u) is processed by activated IRE1. The protein product (bZIP60s) translated from the spliced bZIP60 (bZIPS) is translocated into the nucleus to activate the expression of UPR genes such as chaperones. Different from XBP1u, plant bZIP60u protein, translated from bZIP60u mRNA, is retained in the ER membrane. Sensing unfolded proteins in the ER lumen, bZIP60u undergoes a proteolytic processing, releasing bZIP60s. A recent study has shown that the expression of bZIP60 was increased by PVX infection. However, the roles of the UPR pathway in virus infection have only begun to be investigated in plants. Critical unanswered questions need to be addressed in the future, such as whether viruses modulate the IRE1 pathway via inhibiting the transcriptional activity of bZIP60s (indicated by "?"). 
an XBP1-independent post-transcriptional mechanism for IRE1 to regulate gene expression that remodels the protein repertoire (Figure 4). However, it is unknown whether the mRNA degradation is promoted by IRE1 with its own endonuclease activity. In fact, in metazoans both the precursor and spliced form of XBP1 are translated (Figure 4) (Calfon et al., 2002; Yoshida et al., 2006). The XBP1s is more stable, working as a transactivator of UPR target genes, whereas the unspliced XBP1 (designated $\mathrm{XBP} 1 \mathrm{u}$ ) is labile and inhibits transcription of UPR target genes (Figure 4) (Yoshida et al., 2001; Calfon et al., 2002). By contrast, in yeast, the translation of unspliced HAC1 mRNA is repressed due to the presence of intron, and relief of this repression is the key step in activating the yeast UPR (Rüegsegger et al., 2001).

In human hepatoma cells expressing HCV subgenomic replicons, IRE1 is activated as indicated by elevated accumulation and expression of XBP1s (Tardif et al., 2004). However, the transactivating activity of XBP1s is inhibited and the degradation of misfolded proteins is repressed due to the block of ERAD activity. In addition, in an IRE1-null cell line with a defective IRE1-XBP1 pathway, there is an elevated level of translation mediated by the HCV IRES (internal ribosome entry site), which directs the translation of HCV non-structural proteins (Tardif et al., 2004). Based on these data, it is concluded that HCV may suppress the IRE1$\mathrm{XBP} 1$ pathway to stimulate $\mathrm{HCV}$ expression and to contribute to the persistence of the virus in infected hepatocytes (Tardif et al., 2004). However, the underlying mechanism of the repression of the transcriptional activity of XBP1s by HVC (Figure 4) is unclear. One possible explanation is that in cells carrying HCV replicons, XBP1 itself is targeted for proteasomal degradation, limiting its transcriptional regulation activity (TrujilloAlonso et al., 2011). However, how HCV replicons direct XBP1 to be degraded remains to be understood. In addition to posttranscriptional modification by IRE1, HAC1 and XBP1 are also regulated by the UPR as transcriptional targets. In yeast, HAC1 mRNA production is induced by ER stress (Leber et al., 2004). In metazoan cells, levels of XBP1 mRNA also increase upon UPR induction (Yoshida et al., 2006), leading to accumulation of newly transcribed XBP1 mRNAs in their unspliced form. Therefore, the accumulated XBP1u mRNA may serve as an inhibitor to suppress the IRE1 signaling pathway since the XBP1u is a transcriptional repressor of UPR target genes (Yoshida et al., 2001; Calfon et al., 2002). Moreover, the XBP1u mRNA itself may also terminate the IRE1 signaling pathway by inhibitory heterodimerization with spliced XBP1 and/or competition for binding sites (Yoshida et al., 2006), conferring a switch-like property to XBP1-mediated gene regulation. Thus far, however, it is unknown if $\mathrm{HCV}$ infection increases the level of XBP1u mRNA and thus suppresses the transcriptional activity of XBP1s. Similar to the case of HCV, infection with human CMV or animal SARS-CoV also leads to a progressive increase in XBP1s mRNA; however, its target genes are not induced, suggesting that either the translation or the transcriptional regulation activity of XBP1s is blocked (Isler et al., 2005; Bechill et al., 2008).

A recent study in lung epithelial cell has showed that influenza A virus activates the IRE1 pathway with little or no concomitant activation of the PERK and ATF6 pathways, and inhibition of IRE1 activity leads to decreased viral replication, suggesting that IRE1 is a potential therapeutic target for influenza A virus (Hassan et al., 2012). In this study, influenza A virus replication also leads to an increase in XBP1 mRNA splicing, which can be blocked by the specific inhibitors of the IRE1 pathway. However, it is unclear if activation of IRE1 but inhibition of XBP1s is also used by influenza A virus as a strategy to cope with the IRE1 activation-mediated antiviral responses. In the case of West Nile Virus (WNV), the IRE1-XBP1 pathway is non-essential for its replication, although XBP1s is induced (Medigeshi et al., 2007). In $x b p 1^{-/-}$cells, WNV accumulation is similar to that in the wild type cells, suggesting a possibility that other UPR pathways can compensate for the absence of XBP1 in these cells (Medigeshi et al., 2007). In agreement with these findings, knockdown of XBP1 expression by small interfering RNA has minimal effects on cells' susceptibility to other flaviviruses such as JEV and DEN (Zhao and Ackerman, 2006), although IRE1-XBP1 pathway was activated during the two viruses infection, as evidenced by XBP1 mRNA splicing and protein expression, as well as induction of the downstream genes ERdj4, EDEM1, and p58(IPK) (Yu et al., 2006).

It has been almost one decade since IRE1 homologs were detected in the genomes of Arabidopsis and rice (Koizumi et al., 2001; Okushima et al., 2002). Now, it is clear that the mRNAs of Arabidopsis bZIP60 (AtbZIP60) and its rice ortholog OsbZIP50, collectively called bZIP60, are spliced by IRE1 (Figure 4) (Deng et al., 2011; Nagashima et al., 2011). The bZIP60 mRNA shares similar secondary structure with $\mathrm{HACl}$ and XBP1 mRNA, and they also share a similar splicing mechanism (Figure 4) (Iwata and Koizumi, 2012). Besides being processed conventionally as the mRNA targets of IRE1, which seems conserved in both plants and animals, plant bZIP60 has a unique post-translational modification (Iwata and Koizumi, 2005; Iwata et al., 2008). Plant bZIP60 (unspliced) is synthesized at a low level as a precursor protein, which is anchored in the ER membrane under normal conditions (Figure 4). Sensing ER stress by an as yet to be elucidated mechanism, the N-terminal domain of AtbZIP60 is cleaved and translocated to the nucleus (Figure 4) (Iwata and Koizumi, 2005; Iwata et al., 2008, 2009). In turn, the nuclearlocalized AtbZIP60 forms a transcriptionally active protein complex of approximately $260 \mathrm{kDa}$ to activate the transcription of UPR genes, such as BiP3, via the cis-elements plant-UPR element and ER stress response element (Urade, 2007; Iwata et al., 2009). However, the truncated species of bZIP60 has recently been suggested to be the product translated from the spliced mRNA mediated by IRE1, not the cleaved product of the full-length bZIP60 (Deng et al., 2011; Nagashima et al., 2011). Recently, the role of the bZIP60-mediated UPR has also been demonstrated for the first time in infection by a plant virus. In response to PVX infection or PVX TGBp3 induced-ER stress, bZIP60 is upregulated (Figure 4). Silencing bZIP60 leads to the suppression of the UPR transcript levels and reduces PVX accumulation (Ye et al., 2011). It is suggested that the bZIP60-mediated UPR may be important to regulate cellular cytotoxicity and beneficial to PVX pathogenesis (Ye et al., 2011). However, the mechanism by which bZIP60 is manipulated by the virus and how bZIP60 operates in induction of the UPR are not clear. 


\section{ATF6 AND ER CHAPERONE EXPRESSION}

ATF $6 \alpha$ and ATF6 $\beta$ are the members of type II ER trasmembrane proteins that possess bZIP transcription factor domains in their cytosolic regions (Haze et al., 1999). They are synthesized as inactive precursors, tethered to the ER membrane by an ER-targeting hydrophobic sequence (Figure 5). Unlike PERK and IRE1 which oligomerize upon ER stress, ATF6 translocates from the ER into the Golgi apparatus (Figure 5). Once translocated to the Golgi, it is proteolytically processed by Golgi-resident intramembrane proteases, first by site 1 protease (S1P) and then in an intramembrane region by site 2 protease (S2P) (Figure 5) (Hetz et al., 2011). This proteolytic processing releases its cytoplasmic DNA-binding domain, ATF6f (a fragment of ATF6), which operates as a transcriptional activator that upregulates many UPR genes related to protein folding (Figure 5) (Haze et al., 1999; Lee et al., 2002; Yamamoto et al., 2007).

As mentioned above, replication of HCV subgenomic replicons suppresses the IRE1-XBP1 pathway (Tardif et al., 2002, 2004). However, in cells infected by HCV replicons, subgenomic replication results in the activation of the ATF6 pathway, indicated by the presence of a $50 \mathrm{kDa}$ protein, a cleavage product corresponding to the DNA-binding domain of ATF6 (Tardif et al., 2002, 2004). As a result, there is an increased transcriptional level of chaperones such as BiP. At present, it remains elusive which non-structural viral protein(s) are involved in induction of ATF6, since HVC subgenomic replicons only express the structural proteins. Other experiments suggest that the accumulation of unfolded MHC class I, which is attributed to a decline in protein glycosylation caused by HCV replication, might account for the activation of ATF6 (Tardif and Siddiqui, 2003). Additionally, acute infection with LCMV or expression of its glycoprotein precursor results in a selective induction of the ATF6-regulated pathway of the UPR, whereas pathways controlled by PERK and
IRE1 are silent (Pasqual et al., 2011). It seems that a selective induction of the ATF6-regulated branch of the UPR is likely beneficial for virus replication and cell viability, whereas the induction of PERK and IRE1 may be detrimental for the invading virus and the host cell (Pasqual et al., 2011). Similarly, in Vero cell, ASFV induces the ATF6 signaling pathway, but not the PERK or IRE1 pathways, which might benefit the virus by assisting protein folding and preventing early apoptosis (Galindo et al., 2012).

A different pattern has been reported in cells infected with Hepatitis B virus (HBV) (Li et al., 2007). In Hep3B cells, expression of the multifunctional regulatory protein of $\mathrm{HBV}$ (HBx protein) alone is sufficient to activate both the ATF6 and IRE1-XBP1 pathways, and silencing HBx blocks their activation induced by the constitutive replication of HBV (Li et al., 2007). Therefore, HBx-mediated activation of these two pathways probably promotes HBV replication in liver cells. Similarly, both the IRE1 and ATF6 pathways are activated during Rotavirus infection (TrujilloAlonso et al., 2011). Another scenario has also been found in human lung adenocarcinoma cells where a global UPR activation occurs upon DEN infection (Umareddy et al., 2007). Selective perturbation of the UPR pathways considerably alters DEN infectivity (Umareddy et al., 2007). Although the molecular mechanisms by which DEN infection activates ER stress remain to be elucidated, the three branches of the UPR signaling cascades might be hijacked by DEN to produce a condition beneficial to the viral infection.

Similar to animals, plants have signaling components that function in parallel to the IRE1-bZIP60 signaling cascade (Figure 5) (Urade, 2007; Vitale and Boston, 2008; Deng et al., 2011; Nagashima et al., 2011; Iwata and Koizumi, 2012). In Arabidopsis, bZIP transcription factors bZIP17 and bZIP28 are also synthesized as a precursor protein and anchored in the ER (Figure 5) (Iwata et al., 2008; Seo et al., 2008). In response to

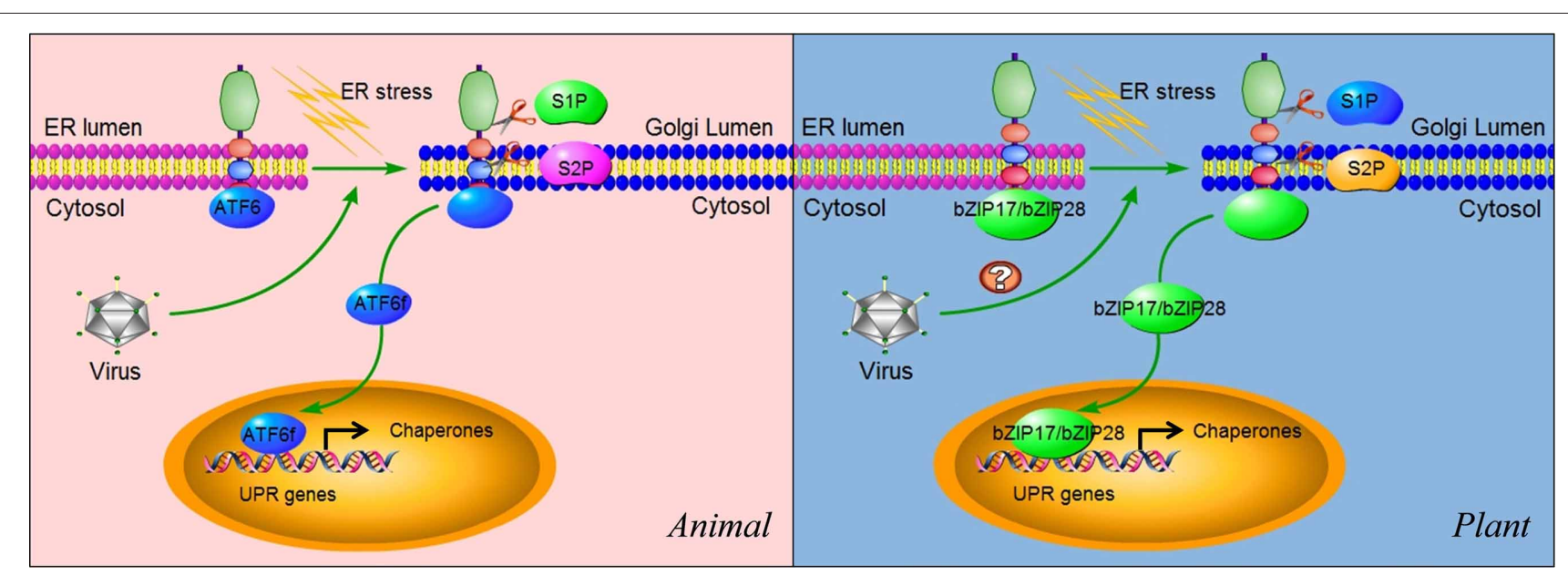

FIGURE 5 | ATF6 and bZIP17/bZIP28 pathways. In unstressed cells, ATF6 in animals and bZIP17/bZIP28 in plants reside in the ER membrane. They are delivered to the Golgi apparatus in an unknown mechanism upon sensing ER stress. In the Golgi apparatus, these proteins are subject to cleavage twice, first by the lumenal S1P and then the intra-membrane S2P, to release the cytosolic effector portions of the proteins (ATF6f). ATF6f then enters into the nucleus and probably activates a subset of UPR target genes, although these remain to be characterized. Some viruses such as ASFV have been shown to selectively activate the ATF6 pathway for their replication in animals. In plants, the cleaved $\mathrm{N}$ terminal portions of bZIP17 and bZIP28 also move into the nucleus and activate UPR genes. In plants, the functional roles of IRE1-bZIP17/bZIP28 in virus infection (indicated by "?") have yet to be elucidated. 
ER stress, bZIP17 and bZIP28 undergo proteolytic processing and translocation in a manner similar to the animal ATF6-S1P/S2P system (Figure 5) (Iwata and Koizumi, 2012). Upon translocated into the nucleus, bZIP17 and bZIP28 activate genes involved in the UPR and other signaling pathways such as brassinosteroid signaling transduction (Che et al., 2010). Although the proteolytic activation of bZIP17 and bZIP28 has been shown to be triggered by heat stress (Urade, 2007; Vitale and Boston, 2008; Deng et al., 2011; Nagashima et al., 2011; Iwata and Koizumi, 2012), no information is available at present about their roles in viral infection. Therefore, our understanding of the plant UPR pathway is very limited, and more efforts are needed to characterize the bZIP17/bZIP28 pathway and its roles in physiological and pathological settings.

\section{CROSSTALK BETWEEN THREE ARMS OF THE UPR}

It is conceivable that IRE1, PERK, and ATF6 pathways communicate with each other extensively in many aspects, including activation, function, and feedback regulation. A seminal work discovering the crosstalk between these three arms comes from Hela cells, where XBP1 mRNA could be induced by ATF6 and spliced by IRE1 in response to ER stress (Yoshida et al., 2001). Moreover, transcriptional activation of XBP1 could be induced by the PERK signaling pathway as well, which might account for the broad effects of PERK during the UPR (Yoshida et al., 2001; Calfon et al., 2002). Besides PERK, IRE1 can also suppress protein translation via degrading mRNA (Hollien and Weissman, 2006; Hollien et al., 2009). In fact, a pro-apoptotic factor CHOP is regulated by both the ATF6 and PERK pathways (Schröder and Kaufman, 2005). While three arms of the UPR have their own specific functions in ER stress (Figures 3, 4, and 5), mutant analyses in C. elegans have revealed that the IRE1-XBP1 and the ATF6 arms of the UPR might activate a common set of genes involved in stress tolerance and worm development, indicating a functional redundancy between these two arms (Shen et al., 2005). Furthermore, all the three arms could induce ERAD (Schröder and Kaufman, 2005), representing a common cellular process resulting from the three UPR branches.

These crosstalks further add to the complexity of the UPR induced by abiotic and biotic cues such viral infection. For example, some viruses, such as HBV, Rotavirus, and DEN, usually activate two or even three pathways to promote reproduction ( $\mathrm{Li}$ et al., 2007; Umareddy et al., 2007; Trujillo-Alonso et al., 2011). The expression of CMV Us11 or CMV infection inhibits the ATF6 pathway but activates the IRE1 pathway as an alternative mechanism to upregulate the expression of chaperones. Meanwhile, the transcriptional activation of the XBP1 target genes (e.g., those encoding protein degradation factors) regulated by the IRE1 pathway is inhibited, presumably in order to keep viral proteins in the ER from being degraded (Tirosh et al., 2005). In this case, it is puzzling how the virus activates the most favorable pathway for its replication and deactivates the molecular signaling pathway that is probably detrimental for its accumulation in the host cell.

So far, two UPR pathways have been identified in plants. Their crosstalk, however, does exist and appear diverse. The expression of AtPDI genes was found to decrease in the AtbZIP60 mutant but not in the AtIRE1-2 mutant, indicating that the additional
UPR signaling complements AtbZIP60 in the activation of AtPDI gene expression during ER stress (Lu and Christopher, 2008). The structural similarity, especially in the putative transmembrane domain of the bZIP60, bZIP17, and bZIP28 proteins (Iwata and Koizumi, 2012), suggests that these two pathways might collaborate closely in sensing ER stress. Indeed, bZIP28 proteolytic activation and bZIP60 mRNA splicing could be induced concomitantly in response to heat stress (Gao et al., 2008; Deng et al., 2011). This assumption is also in agreement with another recent observation that bZIP28 is capable of forming a heterodimer with bZIP60 (Iwata et al., 2009; Liu and Howell, 2010), a direct crosstalk between these two pathways.

\section{CONCLUSION REMARKS}

In higher eukaryotes, many critical biological processes are dependent on intercellular/intracellular communication, which requires relevant proteins timely and adequately expressed with high fidelity in folding. Therefore, the folding function of the ER and the signaling of the ER stress-induced UPR pathways have emerged as an important aspect of cell biology with broad implications to diverse physiological and pathological processes. Despite the recent advances made in understanding the UPR mechanisms implicated in abiotic and biotic stress such as viral infection, many critical questions still remain unanswered. The molecular and structural basis for recognition of the upstream signal by the ER stress sensors has only begun to be understood. Although several recognition models have been proposed mainly based on data using pharmacological chemicals and experimental stress conditions as the inducers of the UPR (Figure 2), we cannot empirically translate this knowledge into the case of viral infection. As discussed above, either virus replication or specific viral proteins (peptides) directly activate the UPR transducers, and different viruses may induce a specific UPR pathway(s). On the other hand, abiotic and biotic ER stress may also share some common UPR pathways that help host cells to defend against those adverse environmental stimuli. A good example is that virus infection can improve plant tolerance to abiotic stress (Xu et al., 2008). A key direction for future study in this field is to define how the ER stress is sensed and how those branched pathways are coordinated to function.

As a complex signal transduction network, the UPR protects the organisms against normal and unusual levels of ER stress by enhancing ER capacity, by reducing ER load, and by inducing programmed cell death. Different cell types may have different levels of sensitivity to ER stress. In response to specific viral infection and other stimuli, little is known about the regulation of UPR signaling in distinct cells, and how the kinetics and amplitude of signaling of each UPR branch is controlled. Our current knowledge about the roles of the downstream effectors of UPR transducers is also limited. For instance, it is unknown how the transcriptional activity of XBP1 is blocked in virus-infected cells (Figure 5). In plants, it is unclear whether the transcriptional activity of spliced bZIP60 is also a target by the invading virus, and whether there is an ERAD-like process responsible for removing spliced bZIP60 mRNA. As the plant IRE1 seems not only just to function through mediating bZIP60 mRNA splicing, its other downstream components remain to be characterized. 
A comprehensive study on these questions will certainly shed new lights in the UPR pathways, and assist in a better understanding of host-virus interactions and, in the long run, developing novel antiviral strategies.

\section{REFERENCES}

Anelli, T., and Sitia, R. (2008). Protein quality control in the early secretory pathway. EMBO J. 27, 315-327.

Aragón, T., Van Anken, E., Pincus, D., Serafimova, I. M., Korennykh, A. V., Rubio, C. A., et al. (2008). Messenger RNA targeting to endoplasmic reticulum stress signalling sites. Nature 457, 736-740.

Balch, W. E., Morimoto, R. I., Dillin, A., and Kelly, J. W. (2008). Adapting proteostasis for disease intervention. Science 319, 916-919.

Baltzis, D., Qu, L. K., Papadopoulou, S., Blais, J. D., Bell, J. C., Sonenberg, N., et al. (2004). Resistance to vesicular stomatitis virus infection requires a functional cross talk between the eukaryotic translation initiation factor $2 \alpha$ kinases PERK and PKR. J. Virol. 78, 12747-12761.

Bechill, J., Chen, Z., Brewer, J. W., and Baker, S. C. (2008). Coronavirus infection modulates the unfolded protein response and mediates sustained translational repression. J. Virol. 82, 4492-4501.

Bertolotti, A., Zhang, Y., Hendershot, L. M., Harding, H. P., and Ron, D. (2000). Dynamic interaction of BiP and ER stress transducers in the unfolded-protein response. Nat. Cell Biol. 2, 326-332.

Boyce, M., Bryant, K. F., Jousse, C., Long, K., Harding, H. P., Scheuner, D., et al. (2005). A selective inhibitor of eIF2 $\alpha$ dephosphorylation protects cells from ER stress. Science 307, 935.

Brewer, J. W., and Hendershot, L. M. (2004). Building an antibody factory: a job for the unfolded protein response. Nat. Immunol. 6, 23-29.

Calfon, M., Zeng, H., Urano, F., Till, J. H., Hubbard, S. R., Harding, H. P., et al. (2002). IRE1 couples endoplasmic reticulum load to secretory capacity by processing the XBP-1 mRNA. Nature 415, 92-96.

Chan, S. W., and Egan, P. A. (2005). Hepatitis $\mathrm{C}$ virus envelope proteins regulate $\mathrm{CHOP}$ via induction of the unfolded protein response. FASEB J. 19, 1510-1512.

Che, P., Bussell, J. D., Zhou, W., Estavillo, G. M., Pogson, B. J., and Smith, S. M. (2010). Signaling from the endoplasmic reticulum activates brassinosteroid signaling and promotes acclimation to stress in
Arabidopsis. Sci. Signal. 3:ra69. doi: 10.1126/scisignal.2001140

Cheng, G., Feng, Z., and He, B. (2005). Herpes simplex virus 1 infection activates the endoplasmic reticulum resident kinase PERK and mediates eIF- $2 \alpha$ dephosphorylation by the $\gamma 134.5$ protein. J. Virol. 79, 1379-1388.

Cheng, G., Gross, M., Brett, M. E. and He, B. (2001). AlaArg motif in the carboxyl terminus of the $\gamma 134.5$ protein of herpes simplex virus type 1 is required for the formation of a high-molecular-weight complex that dephosphorylates eIF- $2 \alpha$. J. Virol. 75, 3666-3674.

Choukhi, A., Ung, S., Wychowski, C., and Dubuisson, J. (1998). Involvement of endoplasmic reticulum chaperones in the folding of hepatitis C virus glycoproteins. J. Virol. 72, 3851-3858.

Connor, J. H., Weiser, D. C., Li, S. Hallenbeck, J. M., and Shenolikar, S. (2001). Growth arrest and DNA damage-inducible protein GADD34 assembles a novel signaling complex containing protein phosphatase 1 and inhibitor 1. Mol. Cell. Biol. 21 , 6841-6850.

Costa, M. D. L., Reis, P. A. B., Valente, M. A. S., Irsigler, A. S. T., Carvalho, C. M., Loureiro, M. E., et al. (2008). A new branch of endoplasmic reticulum stress signaling and the osmotic signal converge on plant-specific asparagine-rich proteins to promote cell death. J. Biol. Chem. 283, 20209-20219.

Cox, J. S., and Walter, P. (1996). A novel mechanism for regulating activity of a transcription factor that controls the unfolded protein response. Cell $87,391-404$.

Credle, J. J., Finer-Moore, J. S., Papa F. R., Stroud, R. M., and Walter, P. (2005). On the mechanism of sensing unfolded protein in the endoplasmic reticulum. Proc. Natl. Acad. Sci. U.S.A. 102, 18773

Deng, Y., Humbert, S., Liu, J. X., Srivastava, R., Rothstein, S. J., and Howell, S. H. (2011). Heat induces the splicing by IRE1 of a mRNA encoding a transcription factor involved in the unfolded protein response in Arabidopsis. Proc. Natl. Acad. Sci. U.S.A. 108, 7247.

Dimcheff, D. E., Faasse, M. A., McAtee, F. J., and Portis, J. L. (2004). Endoplasmic reticulum (ER) stress

\section{ACKNOWLEDGMENTS}

This work was supported by grants from Agriculture and AgriFood Canada and Natural Sciences and Engineering Research Council of Canada.

induced by a neurovirulent mouse retrovirus is associated with prolonged BiP binding and retention of a viral protein in the ER. J. Biol. Chem. 279, 33782.

Dorner, A. J., Wasley, L. C. and Kaufman, R. J. (1992) Overexpression of GRP78 mitigates stress induction of glucose regulated proteins and blocks secretion of selective proteins in Chinese hamster ovary cells. EMBO J. 11 , 1563.

Dorner, A. J., Wasley, L. C., Raney, P., Haugejorden, S., Green, M., and Kaufman, R. J. (1990). The stress response in Chinese hamster ovary cells. Regulation of ERp72 and protein disulfide isomerase expression and secretion. J. Biol. Chem. 265, 22029-22034.

Ellgaard, L., and Helenius, A. (2003). Quality control in the endoplasmic reticulum. Nat. Rev. Mol. Cell Biol. 4, 181-191.

Galindo, I., Hernáez, B., Muñoz Moreno, R., Cuesta-Geijo, M. A., Dalmau-Mena, I., and Alonso, C. (2012). The ATF6 branch of unfolded protein response and apoptosis are activated to promote African swine fever virus infection. Cell Death Dis. 3:e341. doi: 10.1038/cddis.2012.81

Gao, H., Brandizzi, F., Benning, C., and Larkin, R. M. (2008). A membranetethered transcription factor defines a branch of the heat stress response in Arabidopsis thaliana. Proc. Natl. Acad. Sci. U.S.A. 105, 16398-16403.

García-Marcos, A., Pacheco, R. Martiáñez, J., González-Jara, P. Díaz-Ruíz, J. R., and Tenllado, F. (2009). Transcriptional changes and oxidative stress associated with the synergistic interaction between Potato virus $X$ and Potato virus $Y$ and their relationship with symptom expression. Mol. Plant Microbe Interact. 22, 1431-1444.

Gardner, B. M., and Walter, P. (2011) Unfolded proteins are IRE1activating ligands that directly induce the unfolded protein response. Science 333, 1891.

Gething, M. J., McCammon, K., and Sambrook, J. (1986). Expression of wild-type and mutant forms of influenza hemagglutinin: the role of folding in intracellular transport. Cell 46, 939-950.
Harding, H. P., Zhang, Y., and Ron, D. (1999). Protein translation and folding are coupled by an endoplasmic-reticulum-resident kinase. Nature 397, 271-274.

Hassan, I. H., Zhang, M. S., Powers, L. S., Shao, J. Q., Baltrusaitis, J., Rutkowski, D. T., et al. (2012). Influenza A viral replication is blocked by inhibition of the Inositol-requiring Enzyme 1 (IRE1) stress pathway. J. Biol. Chem. 287, 4679-4689.

Haze, K., Yoshida, H., Yanagi, H., Yura, T., and Mori, K. (1999). Mammalian transcription factor ATF6 is synthesized as a transmembrane protein and activated by proteolysis in response to endoplasmic reticulum stress. Mol. Biol. Cell 10, 3787-3799.

He, B. (2006). Viruses, endoplasmic reticulum stress, and interferon responses. Cell Death Differ. 13, 393-403.

He, B., Gross, M., and Roizman, B. (1997). The $\gamma 134.5$ protein of herpes simplex virus 1 complexes with protein phosphatase $1 \alpha$ to dephosphorylate the $\alpha$ subunit of the eukaryotic translation initiation factor 2 and preclude the shutoff of protein synthesis by doublestranded RNA-activated protein kinase. Proc. Natl. Acad. Sci. U.S.A. 94, 843.

He, B., Gross, M., and Roizman, B. (1998). The $\gamma 134.5$ protein of herpes simplex virus 1 has the structural and functional attributes of a protein phosphatase 1 regulatory subunit and is present in a high molecular weight complex with the enzyme in infected cells. J. Biol. Chem. 273, 20737-20743.

He, C., and Klionsky, D. J. (2009) Regulation mechanisms and signaling pathways of autophagy. Annu. Rev. Genet. 43, 67.

Hendershot, L. M. (2004). The ER function $\mathrm{BiP}$ is a master regulator of ER function. Mt. Sinai J. Med. $71,289$.

Hetz, C. (2012). The unfolded protein response: controlling cell fate decisions under ER stress and beyond. Nat. Rev. Mol. Cell Biol. 13, 89-102.

Hetz, C., Bernasconi, P., Fisher, J., Lee, A. H., Bassik, M. C., Antonsson, B. et al. (2006). Proapoptotic BAX and BAK modulate the unfolded protein response by a direct interaction with IRE1 $\alpha$. Science 312, 572 
Hetz, C., Martinon, F., Rodriguez, D., and Glimcher, L. H. (2011). The unfolded protein response: integrating stress signals through the stress sensor IRE1 $\alpha$. Physiol. Rev. 91, 1219-1243.

Hinnebusch, A. G., and Natarajan, K. (2002). Gcn4p, a master regulator of gene expression, is controlled at multiple levels by diverse signals of starvation and stress. Eukaryot. Cell 1, 22-32.

Hollien, J., Lin, J. H., Li, H., Stevens, N., Walter, P., and Weissman, J. S. (2009). Regulated IRE1-dependent decay of messenger RNAs in mammalian cells. J. Cell Biol. 186, 323-331.

Hollien, J., and Weissman, J. S. (2006). Decay of endoplasmic reticulumlocalized mRNAs during the unfolded protein response. Science 313, 104.

Hurtley, S. M., Bole, D. G., HooverLitty, H., Helenius, A., and Copeland, C. S. (1989). Interactions of misfolded influenza virus hemagglutinin with binding protein $(\mathrm{BiP})$. J. Cell Biol. 108, 2117-2126.

Irsigler, A., Costa, M., Zhang, P., Reis, P., Dewey, R., Boston, R., et al. (2007). Expression profiling on soybean leaves reveals integration of ER-and osmotic-stress pathways. BMC Genomics 8:431. doi: 10.1186/1471-2164-8-431

Isler, J. A., Skalet, A. H., and Alwine, J. C. (2005). Human cytomegalovirus infection activates and regulates the unfolded protein response. J. Virol. 79, 6890-6899.

Iwata, Y., Fedoroff, N. V., and Koizumi, N. (2008). Arabidopsis bZIP60 is a proteolysis-activated transcription factor involved in the endoplasmic reticulum stress response. Plant Cell 20, 3107-3121.

Iwata, Y., and Koizumi, N. (2005). An Arabidopsis transcription factor, AtbZIP60, regulates the endoplasmic reticulum stress response in a manner unique to plants. Proc. Natl. Acad. Sci. U.S.A. 102, 5280.

Iwata, Y., and Koizumi, N. (2012). Plant transducers of the endoplasmic reticulum unfolded protein response. Trends Plant Sci. 17, 720-727.

Iwata, Y., Yoneda, M., Yanagawa, Y., and Koizumi, N. (2009). Characteristics of the nuclear form of the Arabidopsis transcription factor AtbZIP60 during the endoplasmic reticulum stress response. Biosci. Biotechnol. Biochem. 73, 865-869.

Jordan, R., Wang, L., Graczyk, T. M., Block, T. M., and Romano, P. R. (2002). Replication of a cytopathic strain of bovine viral diarrhea virus activates PERK and induces endoplasmic reticulum stress-mediated apoptosis of MDBK cells. J. Virol. 76, 9588-9599.

Jousse, C., Oyadomari, S., Novoa, I., Lu, P., Zhang, Y., Harding, H. P. et al. (2003). Inhibition of a constitutive translation initiation factor $2 \alpha$ phosphatase, CReP, promotes survival of stressed cells. J. Cell Biol. 163, 767-775.

Kaneko, M., Niinuma, Y., and Nomura, Y. (2003). Activation signal of nuclear factor- $\kappa \mathrm{B}$ in response to endoplasmic reticulum stress is transduced via IRE1 and tumor necrosis factor receptor-associated factor 2. Biol. Pharm. Bull. 26, 931-935.

Kim, I., Xu, W., and Reed, J. C. (2008). Cell death and endoplasmic reticulum stress: disease relevance and therapeutic opportunities. Nat. Rev. Drug Discov. 7, 1013-1030.

Kimata, Y., Ishiwata-Kimata, Y., Ito, T. Hirata, A., Suzuki, T., Oikawa, D., et al. (2007). Two regulatory steps of ER-stress sensor IRE1 involving its cluster formation and interaction with unfolded proteins. J. Cell Biol. 179, 75-86.

Kimata, Y., Kimata, Y. I., Shimizu, Y., Abe, H., Farcasanu, I. C., Takeuchi, M., et al. (2003). Genetic evidence for a role of $\mathrm{BiP} / \mathrm{Kar} 2$ that regulates IRE1 in response to accumulation of unfolded proteins. Mol. Biol. Cell 14, 2559-2569.

Kimata, Y., Oikawa, D., Shimizu, Y., Ishiwata-Kimata, Y., and Kohno, K. (2004). A role for BiP as an adjustor for the endoplasmic reticulum stress-sensing protein IRE1. J. Cell Biol. 167, 445-456.

Kohno, K., Normington, K., Sambrook, J., Gething, M. J., and Mori, K. (1993). The promoter region of the yeast KAR2 (BiP) gene contains a regulatory domain that responds to the presence of unfolded proteins in the endoplasmic reticulum. Mol. Cell. Biol. 13, 877-890.

Koizumi, N., Martinez, I. M., Kimata, Y., Kohno, K., Sano, H., and Chrispeels, M. J. (2001). Molecular characterization of two Arabidopsis IRE1 homologs, endoplasmic reticulum-located transmembrane protein kinases. Plant Physiol. 127, 949-962.

Korennykh, A. V., Egea, P. F. Korostelev, A. A., Finer-Moore, J., Zhang, C., Shokat, K. M., et al. (2008). The unfolded protein response signals through highorder assembly of IRE1. Nature 457, 687-693.
Leber, J. H., Bernales, S., and Walter, P. (2004). IRE1-independent gain control of the unfolded protein response. PLoS Biol. 2:e235. doi: 10.1371/journal.pbio.0020235

Leborgne-Castel, N., Jelitto-Van Dooren, E. P. W. M., Crofts, A. J., and Denecke, J. (1999). Overexpression of $\mathrm{BiP}$ in tobacco alleviates endoplasmic reticulum stress. Plant Cell 11, 459-469.

Lee, A. H., Iwakoshi, N. N., and Glimcher, L. H. (2003). XBP-1 regulates a subset of endoplasmic reticulum resident chaperone genes in the unfolded protein response. $\mathrm{Mol}$. Cell. Biol. 23, 7448-7459.

Lee, K., Tirasophon, W., Shen, X. Michalak, M., Prywes, R., Okada, T., et al. (2002). IRE1-mediated unconventional mRNA splicing and S2P-mediated ATF6 cleavage merge to regulate $\mathrm{XBP} 1$ in signaling the unfolded protein response. Genes Dev. 16, 452-466.

Li, B., Gao, B., Ye, L., Han, X., Wang, W., Kong, L., et al. (2007). Hepatitis $B$ virus $\mathrm{X}$ protein $(\mathrm{HBx})$ activates ATF6 and IRE1-XBP1 pathways of unfolded protein response. Virus Res. 124, 44-49.

Liberman, E., Fong, Y. L., Selby, M. J. Choo, Q. L., Cousens, L., Houghton, M., et al. (1999). Activation of the grp78 andgrp94 Promoters by Hepatitis C Virus E2 Envelope Protein. J. Virol. 73, 3718-3722.

Liu, J. X., and Howell, S. H. (2010). bZIP28 and NF-Y transcription factors are activated by er stress and assemble into a transcriptional complex to regulate stress response genes in Arabidopsis. Plant Cell 22, 782-796.

Liu, J. X., Srivastava, R., Che, P., and Howell, S. H. (2007). Salt stress responses in Arabidopsis utilize signal transduction pathway related to endoplasmic reticulum stress signaling. Plant J. 51, 897-909.

Lu, D. P., and Christopher, D. A. (2008). Endoplasmic reticulum stress activates the expression of a subgroup of protein disulfide isomerase genes and AtbZIP60 modulates the response in Arabidopsis thaliana. Mol. Genet. Genomics 280, 199-210.

Lu, P. D., Harding, H. P., and Ron, D. (2004). Translation reinitiation at alternative open reading frames regulates gene expression in an integrated stress response. J. Cell Biol. 167, 27-33.

Ma, Y., and Hendershot, L. M. (2003) Delineation of a negative feedback regulatory loop that controls protein translation during endoplasmic reticulum stress. J. Biol. Chem. 278 34864-34873.
Machamer, C. E., Doms, R. W., Bole, D. G., Helenius, A., and Rose, J. K. (1990). Heavy chain binding protein recognizes incompletely disulfidebonded forms of vesicular stomatitis virus G protein. J. Biol. Chem. 265, 6879-6883.

Marcinak, S. J., and Ron, D. (2010). The unfolded protein response in lung disease. Proc. Am. Thorac. Soc. 7, 356-362.

Medigeshi, G. R., Lancaster, A. M., Hirsch, A. J., Briese, T., Lipkin, W. I., DeFilippis, V., et al. (2007). West Nile virus infection activates the unfolded protein response, leading to CHOP induction and apoptosis. J. Virol. 81, 10849-10860.

Meusser, B., Hirsch, C., Jarosch, E., and Sommer, T. (2005). ERAD: the long road to destruction. Nat. Cell Biol. 7, 766-772.

Mori, K., Kawahara, T., Yoshida, H., Yanagi, H., and Yura, T. (1996). Signalling from endoplasmic reticulum to nucleus: transcription factor with a basic-leucine zipper motif is required for the unfolded proteinresponse pathway. Genes Cells 1, 803-817.

Nagashima, Y., Mishiba, K., Suzuki, E., Shimada, Y., Iwata, Y., and Koizumi, N. (2011). Arabidopsis IRE1 catalyses unconventional splicing of bZIP60 mRNA to produce the active transcription factor. Sci. Rep. 1:29. doi: 10.1038/srep00029

Navazio, L., Mariani, P., and Sanders, D. (2001). Mobilization of $\mathrm{Ca}^{2+}$ by cyclic ADP-ribose from the endoplasmic reticulum of cauliflower florets. Plant Physiol. 125, 2129-2138.

Netherton, C. L., Parsley, J. C., and Wileman, T. (2004). African swine fever virus inhibits induction of the stress-induced proapoptotic transcription factor CHOP/GADD153. J. Virol. 78, 10825-10828.

Ng, D. T., Randall, R. E., and Lamb, R. A. (1989). Intracellular maturation and transport of the SV5 type II glycoprotein hemagglutininneuraminidase: specific and transient association with GRP78$\mathrm{BiP}$ in the endoplasmic reticulum and extensive internalization from the cell surface. J. Cell Biol. 109, 3273-3289.

Nomaguchi, M., Fujita, M., and Adachi, A. (2008). Role of HIV$1 \mathrm{Vpu}$ protein for virus spread and pathogenesis. Microbes Infect. 10, 960-967.

Novoa, I., Zhang, Y., Zeng, H., Jungreis, R., Harding, H. P., and Ron, D. (2003). Stress-induced gene expression requires programmed recovery from translational repression. EMBO J. 22, 1180-1187. 
Oikawa, D., Kimata, Y., Kohno, K., and Iwawaki, T. (2009). Activation of mammalian IRE1 $\alpha$ upon ER stress depends on dissociation of $\mathrm{BiP}$ rather than on direct interaction with unfolded proteins. Exp. Cell Res. 315, 2496-2504.

Oikawa, D., Tokuda, M., Hosoda, A., and Iwawaki, T. (2010). Identification of a consensus element recognized and cleaved by IRE $1 \alpha$. Nucleic Acids Res. 38, 6265-6273.

Okushima, Y., Koizumi, N., Yamaguchi, Y., Kimata, Y., Kohno, K., and Sano, H. (2002). Isolation and characterization of a putative transducer of endoplasmic reticulum stress in Oryza sativa. Plant Cell Physiol. 43, 532-539.

Papa, F. R., Zhang, C., Shokat, K., and Walter, P. (2003). Bypassing a kinase activity with an ATP-competitive drug. Science 302, 1533.

Parmar, V. M., and Schröder, M. (2012). Sensing endoplasmic reticulum stress. Adv. Exp. Med. Biol. 738, 153-168.

Pasqual, G., Burri, D. J., Pasquato, A., de la Torre, J. C., and Kunz, S. (2011). Role of the host cell's unfolded protein response in arenavirus infection. J. Virol. 85, 1662-1670.

Pavio, N., Romano, P. R., Graczyk, T. M., Feinstone, S. M., and Taylor, D. R. (2003). Protein synthesis and endoplasmic reticulum stress can be modulated by the hepatitis C virus envelope protein E2 through the eukaryotic initiation factor $2 \alpha$ kinase PERK. J. Virol. 77, 3578-3585.

Pincus, D., Chevalier, M. W., Aragón, T., Van Anken, E., Vidal, S. E., ElSamad, H., et al. (2010). BiP binding to the ER-stress sensor IRE1 tunes the homeostatic behavior of the unfolded protein response. PLoS Biol. 8:e1000415. doi: 10.1371/journal.pbio. 1000415

Preston, A. M., Gurisik, E., Bartley, C., Laybutt, D. R., and Biden, T. J. (2009). Reduced endoplasmic reticulum (ER)-to-Golgi protein trafficking contributes to ER stress in lipotoxic mouse beta cells by promoting protein overload. Diabetologia 52, 2369-2373.

Qiang, X., Zechmann, B., Reitz, M. U., Kogel, K. H., and Schäfer, P. (2012). The mutualistic fungus Piriformospora indica colonizes Arabidopsis roots by inducing an endoplasmic reticulum stresstriggered caspase-dependent cell death. Plant Cell 24, 794-809.

Ron, D., and Walter, P. (2007). Signal integration in the endoplasmic reticulum unfolded protein response. Nat. Rev. Mol. Cell Biol. 8, 519-529.

Rüegsegger, U., Leber, J. H., and Walter, P. (2001). Block of HAC1 mRNA translation by long-range base pairing is released by cytoplasmic splicing upon induction of the unfolded protein response. Cell 107, 103-114.

Schröder, M., and Kaufman, R. J. (2005). The mammalian unfolded protein response. Annu. Rev. Biochem. 74, 739-789.

Seo, P. J., Kim, S. G., and Park, C. M. (2008). Membrane-bound transcription factors in plants. Trends Plant Sci.13, 550-556.

Shaffer, A. L., Shapiro-Shelef, M., Iwakoshi, N. N., Lee, A. H., Qian, S. B., Zhao, H., et al. (2004). XBP1, downstream of Blimp-1, expands the secretory apparatus and other organelles, and increases protein synthesis in plasma cell differentiation. Immunity 21, 81-93.

Shamu, C. E., and Walter, P. (1996). Oligomerization and phosphorylation of the IRE1p kinase during intracellular signaling from the endoplasmic reticulum to the nucleus. EMBO J. 15, 3028.

Shen, J., Chen, X., Hendershot, L., and Prywes, R. (2002). ER stress regulation of ATF6 localization by dissociation of BiP/GRP78 binding and unmasking of Golgi localization signals. Dev. Cell 3, 99-111.

Shen, X., Ellis, R. E., Sakaki, K., and Kaufman, R. J. (2005). Genetic interactions due to constitutive and inducible gene regulation mediated by the unfolded protein response in C. elegans. PLoS Genet. 1:e37. doi: 10.1371/journal.pgen.0010037

Schott, A., Ravaud, S., Keller, S., Radzimanowski, J., Viotti, C., Hillmer, S., et al. (2010). Arabidopsis stromal-derived Factor 2 (SDF2) is a crucial target of the unfolded protein response in the endoplasmic reticulum. J. Biol. Chem. 285, 18113-18121.

Schubert, U., Antón, L. C., Baèík, I., Cox, J. H., Bour, S., Bennink, J. R., et al. (1998). CD4 glycoprotein degradation induced by human immunodeficiency virus type $1 \mathrm{Vpu}$ protein requires the function of proteasomes and the ubiquitinconjugating pathway. J. Virol. 72, 2280-2288.

Sidrauski, C., Cox, J. S., and Walter, P. (1996). tRNA ligase is required for regulated mRNA splicing in the unfolded protein response. Cell 87, 405-413.

Sidrauski, C., and Walter, P. (1997). The transmembrane kinase IRE1p is a site-specific endonuclease that initiates mRNA splicing in the unfolded protein response. Cell 90, 1031-1039.

Stephens, S. B., Dodd, R. D., Brewer J. W., Lager, P. J., Keene, J. D., and Nicchitta, C. V. (2005). Stable ribosome binding to the endoplasmic reticulum enables compartmentspecific regulation of mRNA translation. Mol. Biol. Cell 16, 5819-5831.

Stevens, F. J., and Argon, Y. (1999). Protein folding in the ER. Semin. Cell Dev. Biol. 10, 443-454.

Su, H. L., Liao, C. L., and Lin, Y. L. (2002). Japanese encephalitis virus infection initiates endoplasmic reticulum stress and an unfolded protein response. J. Virol. 76, 4162-4171.

Sun, M., Rothermel, T. A., Shuman, L., Aligo, J. A., Xu, S., Lin, Y., et al. (2004). Conserved cysteine-rich domain of paramyxovirus simian virus $5 \mathrm{~V}$ protein plays an important role in blocking apoptosis. J. Virol. 78, 5068-5078.

Sung, S. C., Chao, C. Y., Jeng, K. S., Yang, J. Y., and Lai, M. (2009). The $8 \mathrm{ab}$ protein of SARS-CoV is a luminal ER membrane-associated protein and induces the activation of ATF6. Virology 387, 402-413.

Tabas, I., and Ron, D. (2011). Integrating the mechanisms of apoptosis induced by endoplasmic reticulum stress. Nat. Cell Biol. 13, 184-190.

Tardif, K. D., Mori, K., Kaufman, R. J., and Siddiqui, A. (2004) Hepatitis $C$ virus suppresses the IRE1-XBP1 pathway of the unfolded protein response. J. Biol. Chem. 279, 17158-17164

Tardif, K. D., Mori, K., and Siddiqui, A. (2002). Hepatitis C virus subgenomic replicons induce endoplasmic reticulum stress activating an intracellular signaling pathway. J. Virol. 76, 7453-7459.

Tardif, K. D., and Siddiqui, A. (2003) Cell surface expression of major histocompatibility complex class I molecules is reduced in hepatitis $\mathrm{C}$ virus subgenomic repliconexpressing cells. J. Virol. 77, 11644-11650.

Tardif, K. D., Waris, G., and Siddiqui, A. (2005). Hepatitis C virus, ER stress, and oxidative stress. Trend Microbiol. 13, 159-163.

Tirosh, B., Iwakoshi, N. N., Lilley, B. N., Lee, A. H., Glimcher, L. H. and Ploegh, H. L. (2005). Human cytomegalovirus protein US11 provokes an unfolded protein response that may facilitate the degradation of class I major histocompatibility complex products. J. Virol. 79, 2768-2779.
Todd-Corlett, A., Jones, E., Seghers, C., and Gething, M. J. (2007). Lobe IB of the ATPase domain of Kar2p/BiP interacts with IER1p to negatively regulate the unfolded protein response in Saccharomyces cerevisiae. J. Mol. Biol. 367, 770-787.

Trujillo-Alonso, V., Maruri-Avidal, L. Arias, C. F., and López, S. (2011). Rotavirus infection induces the unfolded protein response of the cell and controls it through the nonstructural protein NSP3. J. Virol. 85, 12594-12604.

Umareddy, I., Pluquet, O., Wang, Q. Y., Vasudevan, S. G., Chevet, E., and $\mathrm{Gu}, \mathrm{F}$. (2007). Dengue virus serotype infection specifies the activation of the unfolded protein response. Virol. J. 4:91. doi: 10.1186/1743-422X-4-91

Urade, R. (2007). Cellular response to unfolded proteins in the endoplasmic reticulum of plants. FEBS J. 274, 1152-1171.

Urano, F., Wang, X. Z., Bertolotti, A., Zhang, Y., Chung, P., Harding, H. P., et al. (2000). Coupling of stress in the ER to activation of JNK protein kinases by transmembrane protein kinase IRE1. Science 287, 664

Vattem, K. M., and Wek, R. C. (2004). Reinitiation involving upstream ORFs regulates ATF4 mRNA translation in mammalian cells. Proc Natl. Acad. Sci. U.S.A. 101, 11269.

Verchot, J. (2012). Cellular chaperones and folding enzymes are vital contributors to membrane bound replicaiton and movement complexes during RNA virus infection. Front. Plant Sci. 3:275. doi: 10.3389/fpls.2012.00275

Vitale, A., and Boston, R. S. (2008). Endoplasmic reticulum quality control and the unfolded protein response: insights from plants. Traffic 9, 1581-1588.

Wang, D., Weaver, N. D., Kesarwani, M., and Dong, X. (2005). Induction of protein secretory pathway is required for systemic acquired resistance. Science 308, 1036

Wang, X. Z., Lawson, B., Brewer, J. W., Zinszner, H., Sanjay, A., Mi, L. J., et al. (1996). Signals from the stressed endoplasmic reticulum induce C/EBP-homologous protein (CHOP/GADD153). Mol. Cell. Biol. 16, 4273-4280.

Watowich, S. S., Morimoto, R. I., and Lamb, R. A. (1991). Flux of the paramyxovirus hemagglutininneuraminidase glycoprotein through the endoplasmic reticulum activates transcription of the GRP78-BiP gene. J. Virol. 65, 3590-3597. 
Whitham, S. A., Quan, S., Chang, H. S., Cooper, B., Estes, B., Zhu, T., et al. (2003). Diverse RNA viruses elicit the expression of common sets of genes in susceptible Arabidopsis thaliana plants. Plant J. 33, 271-283.

Xu, C. (2005). Endoplasmic reticulum stress: cell life and death decisions. J. Clin. Invest. 115, 2656-2664.

Xu, P., Chen, F., Mannas, J. P., Feldman, T., Sumner, L. W., and Roossinck, M. J. (2008). Virus infection improves drought tolerance. New Phytol. 180, 911-921.

Yamamoto, K., Sato, T., Matsui, T., Sato, M., Okada, T., Yoshida, H., et al. (2007). Transcriptional induction of mammalian er quality control proteins is mediated by single or combined action of ATF $6 \alpha$ and XBP1. Dev. Cell 13, 365-376.

Yang, C., Guo, R., Jie, F., Nettleton, D., Peng, J., Carr, T., et al. (2007). Spatial analysis of Arabidopsis thaliana gene expression in response to Turnip mosaic virus infection. Mol. Plant Microbe Interact. 20, 358-370.

Ye, C., Chen, S., Payton, M., Dickman, M. B., and Verchot, J. (2012). TGBp3 triggers the unfolded protein response and SKP1dependent programmed cell death. Mol. Plant. Pathol. [Online]. doi: 10.1111/mpp. 12000

Ye, C., Dickman, M. B., Whitham, S. A., Payton, M., and Verchot, J. (2011). The unfolded protein response is triggered by a plant viral movement protein. Plant Physiol. 156, 741-755.

Ye, C., and Verchot, J. (2011). Role of unfolded protein response in plant virus infection. Plant Signal. Behav. 6, 1212-1215

Yoshida, H. (2007). ER stress and diseases. FEBS J. 274, 630-658.

Yoshida, H., Matsui, T., Yamamoto, A., Okada, T., and Mori, K. (2001). XBP1 mRNA is induced by ATF6 and spliced by IRE1 in response to ER stress to produce a highly active transcription factor. Cell 107, 881-891.

Yoshida, H., Oku, M., Suzuki, M., and Mori, K. (2006). pXBP1 (U) encoded in XBP1 pre-mRNA negatively regulates unfolded protein response activator pXBP1 (S) in mammalian ER stress response. J. Cell Biol. 172, 565-575.

Yu, C. Y., Hsu, Y. W., Liao, C. L., and Lin, Y. L. (2006). Flavivirus infection activates the XBP1 pathway of the unfolded protein response to cope with endoplasmic reticulum stress. J. Virol. 80, 11868-11880.

Zhang, K., and Kaufman, R. J. (2006). The unfolded protein response: a stress signaling pathway critical for health and disease. Neurology 66, S102-S109.

Zhao, L., and Ackerman, S. L. (2006). Endoplasmic reticulum stress in health and disease. Curr. Opin. Cell Biol. 18, 444-452.

Zhou, J., Liu, C. Y., Back, S. H., Clark, R. L., Peisach, D., Xu, Z., et al. (2006). The crystal structure of human IRE1 luminal domain reveals a conserved dimerization interface required for activation of the unfolded protein response. Proc. Natl. Acad. Sci. U.S.A. 103, 14343-14348.

Zinszner, H., Kuroda, M., Wang, X Z., Batchvarova, N., Lightfoot, R. T., Remotti, H., et al. (1998) CHOP is implicated in programmed cell death in response to impaired function of the endoplasmic reticulum. Genes Dev. 12, 982-995.

Zsak, L., Lu, Z., Kutish, G. F., Neilan, J. G., and Rock, D. L. (1996). An African swine fever virus virulence-associated gene NL-S with similarity to the herpes simplex virus ICP34. 5 gene. J. Virol. 70, 8865-8871.

Conflict of Interest Statement: The authors declare that the research was conducted in the absence of any commercial or financial relationships that could be construed as a potential conflict of interest.

Received: 25 September 2012; accepted: 08 December 2012; published online: 28 December 2012.

Citation: Zhang L and Wang A (2012) Virus-induced ER stress and the unfolded protein response. Front. Plant Sci. 3:293. doi: 10.3389/fpls.2012.00293

This article was submitted to Frontiers in Plant-Microbe Interaction, a specialty of Frontiers in Plant Science.

Copyright (c) 2012 Zhang and Wang. This is an open-access article distributed under the terms of the Creative Commons Attribution License, which permits use, distribution and reproduction in other forums, provided the original authors and source are credited and subject to any copyright notices concerning any third-party graphics etc. 


\section{GLOSSARY}

Molecular chaperone: A molecular chaperone is a protein that assists the folding/unfolding of other proteins. Some molecular chaperones reside in the lumen of the ER, such as BiP, also known as GRP78, a member of the Hsp70 family.

Protein disulphide isomerase (PDI): A cellular enzyme in the lumen of the ER of eukaryotes or the periplasmic region of prokaryotes catalyzes the formation and breakage of disulphide bonds between cysteine residues within proteins, allowing proteins to quickly find the correct arrangement of disulfide bonds in their fully folded state.

ER stress: An organelles-initiated cell stress arises from mismatch between the load of unfolded or misfolded proteins in the lumen of the ER and the capacity of this cellular machinery.

Unfolded protein response (UPR): A highly conserved physiological response is induced by accumulation of unfolded proteins in the lumen of the ER. In mammals, the UPR is mediated by three ER stress sensors including IRE1, PERK, and ATF6. In yeast, the UPR is controlled by only one signaling pathway mediated by IRE1. Thus far, two UPR pathways have been identified in plants, one mediated by IRE1-bZIP60 and the other by bZIP17/bZIP28.

ER-assisted degradation (ERAD): ERAD is designated a cellular pathway, which translocates the unfolded proteins from the ER in a retrograde manner into the cytosol, where ER membrane associated ubiquitin ligases post-translationally modify the translocated proteins thereby targeting them for degradation, usually by the $26 \mathrm{~S}$ proteasome.

Programmed cell-death (PCD): The term PCD defines any form of cell death resulting from an orderly cascade, mediated by intracellular death programs, regardless of the triggers or the hallmarks it exhibits. PCD serves fundamental functions in both plants, and metazoans where called apoptosis.

Major histocompatibility complex (MHC): An integral membrane protein complex has a characteristic groove as the binding site for the presentation of immunogenic peptides.

Hemagglutinin-neuraminidase (HN): A single viral envelope glycoprotein has both receptor-cleaving and receptor-binding activity, which is in contrast to the protein found in influenza, where both hemagglutinin and neuraminidase activities reside in two separate glycoproteins.

Eukaryotic translation initiation factor 2 (eIF2): The eIF2 complex is required in the translation initiation. It transfers MettRNA to the 40S submit of the ribosome to form the $43 \mathrm{~S}$ pre-initiation complex in a GTP-dependent manner. eIF2 is a heterotrimer consisting of eIF2 $\alpha$, eIF2 $\beta$, and eIF $2 \gamma$. Phosphorylation of eIF2 $\alpha$ by PERK inactivates eIF2 $\alpha$, resulting in inhibition of cap-dependent translation initiation.

Unconventional processing: Conventional splicing is catalyzed by the spliceosome, which is composed of multiple proteins and small nuclear RNAs, and the cleavage reaction proceeds sequentially. The nucleotide sequence at the exon-intron border complies with Chambon's rule (GU-AG rule). In contrast, unconventional splicing is catalyzed by IRE1 and tRNA ligase, which is independent of the spliceosome, and the order of cleavage of the exon-intron junctions is not predetermined. A pair of characteristic stem-loop structures exists at the cleavage sites, which is recognized by IRE1, instead of a consensus sequence such as GU-AG. 